\title{
An Experimental Analysis of Contingent Capital with Market-Price Triggers
}

\author{
Douglas Davis, Virginia Commonwealth University \\ Oleg Korenok, Virginia Commonwealth University \\ Edward Simpson Prescott, Federal Reserve Bank of Richmond* ${ }^{\dagger}$
}

April 30, 2013

\begin{abstract}
We report an experiment that evaluates three market-based regimes for triggering the conversion of contingent capital bonds into equity: a "fixed-trigger" regime, where a price threshold triggers mandatory conversion, a "regulator" regime, where regulators make conversion decisions based on prices and a "prediction-market" regime, where regulators also observe a market that predicts conversion. Consistent with theory, we observe inefficiencies and conversion errors in the fixedtrigger and regulator regimes. The prediction market somewhat improves the regulator's performance, but inefficiencies and conversion errors persist. The regulator regime has conversion errors over the widest range of shocks.
\end{abstract}

Keywords: bank regulation; experiments; contingent capital

JEL codes: C92; G14; G28

\footnotetext{
* The authors thank for their useful comments Vinod Changarath , Asen Ivanov, Edward Millner, Robert Reilly, Zhenyu Wang, an anonymous referee, and participants in seminars at the Federal Reserve Banks of New York and Richmond, the Bank of England, the Department of Finance in the Said School of Business at Oxford University, the Department of Economics at the University of Manchester, the School of Business at Virginia Commonwealth University, and conference participants at the Second LeeX International Conference on Theoretical and Experimental Macroeconomics, the 2011 SAET conference, the 2012 Southern Economics Association Meetings, the 2012 Federal Reserve Bank of Cleveland's Conference on Capital Requirements for Financial Firms and the 2012 FIRS conference. The usual disclaimer applies. Financial assistance from the National Science Foundation (SES 1024357), the Federal Reserve Bank of Richmond, and the Virginia Commonwealth University Summer Research Grants Program is gratefully acknowledged. Contact information: Douglas Davis, Department of Economics, 3147 Snead Hall, VCU, Richmond, VA 23284, dddavis@vcu.edu; Oleg Korenok, Department of Economics, 3129 Snead Hall, VCU, Richmond, VA 23284, okorenok@vcu.edu; Edward Simpson Prescott, Research Department, Federal Reserve Bank of Richmond, P.O. Box 27622, Richmond, VA 23261, Edward.Prescott@rich.frb.org.

${ }^{\dagger}$ The views expressed in this paper do not necessarily reflect those of the Federal Reserve Bank of Richmond or the Federal Reserve System.
} 


\section{Introduction.}

In the aftermath of the 2008 financial crisis, a primary focus of financial regulatory reform has been on developing policies to ensure that banks have equity cushions sufficient to maintain solvency in times of financial distress, thus reducing the chance of collapse and taxpayer-funded bailout. ${ }^{1}$ One innovative proposal that has received particular attention is to require that banks carry on their balance sheets a new class of subordinated debt that converts to equity in times of financial distress. ${ }^{2}$ These “contingent capital” bonds have several properties that are beneficial to a bank and to society. They reduce the debt overhang problem by automatically raising equity, precisely when raising equity is most difficult and they act as a partial, pre-packaged bank reorganization by automatically recapitalizing the bank when it is in danger of failing. ${ }^{3}$ These advantages were of sufficient appeal in the U.S. for Congress to mandate a study of the characteristics of contingent capital in the Dodd-Frank Wall Street Reform and Consumer Protection Act of 2010 and in the U.K. for the Independent Commission on Banking to recommend that banks use loss-absorbing debt like contingent capital in their capital structure.

Perhaps the most challenging issue for implementing contingent capital is determining what trigger to use for conversion. ${ }^{4}$ Some proposals rely on accounting measures, but a problem with accounting measures is that they are typically backward looking and lag a bank’s actual condition. By the time they are triggered, it may be too late. ${ }^{5}$

\footnotetext{
${ }^{1}$ Many of the proposed regulatory changes to capital requirements have focused on making them higher and procyclical. Indeed, some commentators argue that capital requirements should be much higher (e.g., Admati, DeMarzo, Hellwig and Pfleiderer, 2010).

${ }^{2}$ For examples of proposals and discussions of contingent capital see Raviv (2004), Flannery (2005), Flannery (2009), Squam Lake Group (2009), Pennacchi, Vermaelen, and Wolf (2013), Plosser (2010), Calomeris and Herring (2011), McDonald (2011) and Pennacchi (2011). Contingent capital should not be viewed as an alternative to raising capital requirements, but as complement. Higher capital requirements may make a bank less likely to encounter financial distress, but at a cost. A variety of theories in corporate finance suggest that equity is an expensive source of funds (e.g., Maljuf and Myers, 1984).

${ }^{3}$ Another potential benefit of contingent capital bonds is that they may give incentives to equity holders to reduce excessive risk taking, since conversion can punish equity owners, at least when it dilutes existing equity (e.g., Calomirs and Herring, 2011).

${ }^{4}$ See Calomiris and Herring (2011) for a list of the various triggers. See Prescott (2012) for a discussion of them.

${ }^{5}$ The prompt corrective action (PCA) provision of the Federal Deposit Insurance Corporation Improvement Act of 1991 is an accounting-based trigger system for banks in the United States. Under PCA, a bank whose regulatory capital drops below certain ratios is restricted from certain activities and if the ratio drops enough it will be required to recapitalize. Despite PCA, costs to resolve failed banks in the recent crisis have been very large partly becauseaccounting measures lagged actual conditions (GAO, 2011).
} 
An appealing alternative to accounting measures is to use market prices as a trigger because prices are forward looking and incorporate the expectations of market participants. ${ }^{6}$ Furthermore, implementation of this type of trigger is less susceptible to political pressures since prices are generally publicly observed. For these reasons and others, a group of academics advocate the use of a market price trigger (e.g., Flannery, 2009; McDonald, 2011; and Calomiris and Herring, 2011).

The small theoretical literature on using market-prices as a trigger, however, finds that in rational expectations models a trigger creates its own set of problems. Sundaresan and Wang (2011) ('SW') study contingent capital with a fixed-price trigger. They show under quite general conditions that if conversion automatically occurs when the price of equity drops below some number, then for some fundamental values no unique price exists for equity. They interpret this inability to price equity as a significant problem for implementing contingent capital.

Birchler and Facchinetti (2007) ('BF') and Bond, Goldstein and Prescott (2010) ('BGP') consider a related problem where, instead of a fixed-price trigger, a regulator chooses to intervene in the activities of a bank based on what he can infer about the bank's condition from market prices. These authors also find non-existence of a rational expectations equilibrium in the case where intervention increases the value of the security. However, $B G P$ also show that if there is a prediction market in whether the regulator intervenes then an equilibrium exists.

This paper builds on these theoretical studies by providing laboratory experimental evidence on the costs of implementing contingent capital with a market-based trigger. This source of data is particularly valuable because there is no financial market evidence on this type of trigger. ${ }^{7}$ In the experiments traders trade a security, the value of which is affected by a contingent-capital like conversion. We examine three regimes: (i) A "Fixed-Trigger" regime where crossing a publicly known price threshold triggers a mandatory conversion; (ii) A "Regulator" regime, where an imperfectly informed, but socially motivated regulator makes conversion decisions based on the price; and (iii) A "Prediction Market" regime where we supplement the information available to agents (both regulators and traders) with traders'

\footnotetext{
${ }^{6}$ It is well documented in the empirical banking literature that bank security prices contain information that predicts changes in bank supervisory ratings. See the survey in Flannery (1998).

${ }^{7}$ Sundaresan and Wang (2011) report four issuances of contingent capital bonds, all since the recent financial crisis, but these issuances use accounting triggers like equity capital.
} 
perceptions of the likelihood of a conversion. ${ }^{8}$ In each regime we consider the case where the conversion transfers value from holders of contingent capital bonds to equity owners ("valueincreasing conversions” for equity owners), as well as the case where the reverse occurs and conversion transfers value away from equity owners to holders of contingent capital bonds (“value-decreasing conversions" for equity owners). ${ }^{9}$

Our experiment design does not explicitly include contingent bonds. Traders exchange a single asset ("equity”) whose value is affected by conversion of such bonds, but the bonds are left outside the experiment. This means we cannot address some questions in the contingent capital debate such as the risk of “death spirals” induced by contingent capital bond holders mounting "bear raids" to drive down the price of equity and force conversion. We also cannot directly address in general more complicated contingent capital proposals that include the price of additional securities or additional decisions by security holders (e.g., Pennacchi, Vermaelen, and Wolf, 2013). Nevertheless, the main issue with a trigger is the discrete change in the value of the traded security caused by conversion, so as long as conversion leads to a similar discrete change in the triggering conditions, our results will be applicable. ${ }^{10}$ Furthermore, our simple structure has the advantage of allowing us to cleanly identify the effects of using a price trigger, without worrying that we are measuring additional phenomenon.

Our experimental results indicate that concerns about the potential for informational inefficiencies are well founded and merit prominent consideration in the debate over the appropriate conversion trigger. Relative to a base condition where no capital conversions occur, a fixed price trigger generates informational efficiency losses in the sense that prices fail to

\footnotetext{
${ }^{8}$ It should be noted that our regulator treatments are not designed to study the regulator's commitment problem, a problem that worries some advocates of price triggers. Instead our regulator treatments study the effectiveness of regulator reactions to prices as well as how the regulator's reactions influence the informational content of prices. Our regulator has some discretion in the sense that he cannot announce a conversion rule that depends on the price and must therefore make a judgment in response to each observed price. However, discretion based on political pressures is not present in these treatments.

${ }^{9}$ Both value-increasing and value-decreasing conversion scenarios are quite possible and depend on the bond-toequity conversion ratio. For example, suppose that there a lot of shares and a contingent capital bond valued at $\$ 10.00$ converts to a share of equity when the share price falls to $\$ 5.00$. Upon conversion, the bank retires $\$ 10$ of debt at a very low cost in terms of equity dilution, thus raising the value of equity. An identical conversion, but with a much higher bond-to-equity conversion ratio would retire the same $\$ 10.00$ of debt at a far higher equity dilution cost, thus reducing the value of equity for incumbent equity holders.

${ }^{10}$ For example, our analysis is applicable to a trigger that is based on the total value of a bank (e.g., Raviv, 2004,and Pennacchi, 2011). A trigger that depends on the total value of the bank avoids discrete changes in value from conversion only if the value of the bank does not depend on the debt structure of the bank. We believe that such an assumption is not relevant here because one of the main benefits of contingent capital is to reduce debt overhang, which implicitly assumes that the value of the bank does depend on the debt structure of the bank.
} 
closely track the underlying asset value. These losses arise in the cases of both value-increasing and value-decreasing conversions, as predicted by $S W$. As a consequence, numerous errant conversion actions occur. Placing the conversion decision in the hands of a regulator fails to improve informational efficiency, and results in conversion errors for an even wider range of fundamental realizations than is observed with a fixed trigger. As in the Fixed-Trigger regime, conversion errors occur both in the case of value-increasing conversions (as predicted by BGP) and in the case of value-decreasing conversions (not predicted by BGP). Similarly, while supplementing the information available to monitors and traders with results of a prediction market improves informational efficiency, the prediction market largely fails to reduce the overall incidence of conversion errors (again not predicted by BGP).

We do observe, however, that relative to the Regulator regime, the Fixed-Trigger and Prediction Market regimes narrow considerably the ranges of fundamental realizations where conversion errors occur. For this reason either a prediction market, or an operationally simpler, and politically less manipulatable fixed trigger rule may be preferable to reliance on the decisions of a discretionary regulator.

Prior to continuing, we observe that the use of experimental methods to examine the potential effects of regulatory proposals offers some important advantages. Laboratory experiments are far less costly than naturally occurring social experiments. Further, only in the laboratory can the investigator observe directly the relationship between fundamentals and asset prices, a relationship that is inherently unobservable in natural contexts. Indeed, in contingent capital proposals it is the unobservability of fundamentals that partly drives recommendations that regulators use asset prices as a reflection of value. Our ability to set fundamentals and then observe trading prices allows us to assess directly the information loss in prices associated with the possibility of intervention, as well as the extent to which regulators in the various regimes err. The low cost and additional control of laboratory experimentation make it an ideal test-bed for evaluating potential effects of regulatory proposals, and that is our primary objective here. ${ }^{11}$

The remainder of this paper is organized as follows. Section 2 reviews theoretical predictions in the context of our experimental design. Section 3 describes the experiment design

\footnotetext{
${ }^{11}$ Laboratory experiments have been used to evaluate market institutions and regulatory structures in a variety of contexts, including markets for gastroenterology fellowships (Niederle and Roth, 2005), pollution emission trading schemes (e.g, Cason, Gangadharan and Duke, 2003), markets for water irrigation rights (Cummings, Holt and Laury, 2004) and the design of radio-spectrum auctions (e.g., Plott and Salmon, 2004).
} 
and procedures. Section 4 presents experimental results. The final section provides some concluding comments.

\section{Market-Based Conversion Policies.}

Market-based regulations depend on prices, which are forward looking because they depend on the expectations of traders about conversions. In a competitive price taking model with rational expectations, $B F, B G P$, and $S W$ found that the feedback between prices and conversion expectations can in some circumstances cause multiple equilibria and in others cause equilibrium to not exist. This section illustrates their findings with a simple model. The experiment design is based on this model, so we will use it to help interpret the results. However, our experiment design also contains several differences from and additions to the model that will be described later, and these will also be factors in the interpretation of results.

2.1 A Fixed-Trigger Regime. Many contingent capital proposals use a fixed price rule as a conversion trigger. For example, if the price of equity drops below a threshold, contingent capital will convert to equity at some ratio. The advantages of such a rule are that it is automatic and easy to verify. However, $S W$ found that a fixed conversion rule can create two problems. First, if conversion decreases the value of equity, the possibility of conversion can create multiple equilibria. Second, if conversion increases the value of equity then for a range of fundamental realizations no equilibrium exists. ${ }^{12,13}$

Suppose that a bank's fundamental value is randomly drawn from a uniformly distributed range of values between $\$ 2.00$ and $\$ 8.00$, and that this fundamental realization $\theta$ is known (collectively) by traders. We consider two conversion scenarios. In a first, value-decreasing scenario the bond-to-equity conversion ratio is set sufficiently low that the conversion transfers $\omega=\$ 2.00$ of share value away from incumbent equity owners to contingent capital bondholders. Consequently the post-conversion equity value becomes $\theta-\omega$. In a second, value-increasing

\footnotetext{
${ }^{12}$ Most analyses of conversion rules focus on value-decreasing conversions, under the argument that a punitive conversion will provide a bank with correct risk management incentives. Nevertheless, the value-increasing scenario is more than a theoretical concern. As observed above in footnote 9 , it is entirely possible that states of the world can arise where conversion would increase equity value. BGP provide a variety of additional regulatory actions that could increase the value of equity.

${ }^{13} \mathrm{In} S W$, a unique equilibrium exists only if conversion transfers no value between equity and other bank liabilities. As $S W$ argue, satisfying this necessary condition is problematic, and it certainly cannot be implemented with a fixed trigger and a fixed conversion ratio. Thus the transfer-of-value cases described in the text are the more relevant ones.
} 
scenario the bond-to-equity conversion ratio is set at a level high enough that contingent capital bond holders transfer $\omega=\$ 2.00$ of value per share to incumbent equity owners, making the postconversion equity value $\theta+\omega$. In both scenarios, conversion is assumed to be socially desirable if $\theta<\$ 5.00$. Correspondingly, the trigger is set at $\hat{\theta}=\$ 5.00$; if the price of equity drops below \$5.00 conversion occurs.

Consider first a value-decreasing conversion. The potential for multiple equilibria can be understood by considering a market fundamental slightly above $\$ 5.00$, say $\$ 5.50$. Given that the fundamental value exceeds $\$ 5.00$, traders, confident that no conversion will occur, should trade at prices close $\$ 5.50$. In this case, no conversion takes place, making traders’ ex ante beliefs correct and thus establishing an equilibrium. Suppose, however, that given the same \$5.50 market fundamental traders for some reason expect a conversion to take place. If traders incorporate the value of the conversion into their bids and offers the price will fall to $\$ 3.50$, triggering a conversion, in this way again making the traders' ex ante belief correct and thus also establishing an equilibrium. Multiple equilibria similarly arise for any market fundamental in the $[\$ 5.00, \$ 7.00)$ range.

Now, consider the case of a value-increasing conversion. The problem of equilibrium nonexistence can be seen by supposing that the fundamental realization is less than $\$ 5.00$. For specificity, suppose that the market fundamental is $\theta=\$ 3.50$, as shown in Figure 1. Traders, aware that equity is worth $\$ 5.50$ if transaction prices remain below the trigger, face a conundrum. If traders assume that a conversion will occur, then the value equals $\$ 5.50$, above the trigger. Alternatively, if they assume that there will be no conversion then the price is $\$ 3.50$, which sets off conversion. Thus, no equilibrium exists. This existence problem arises for any fundamental in the $[\$ 3.00, \$ 5.00)$ range.

2.2 A Regulator Regime. BF and BGP study the related problem of a regulator who does not know the fundamental, but tries to infer it from the price. Furthermore, they assume that the regulator has a fixed underlying market fundamental value for which conversions are desirable, giving him trigger-like preferences. Suppose here that the regulator wants to convert if the fundamental is below $\$ 5.00$, but not if it is above. ${ }^{14}$

\footnotetext{
${ }^{14}$ Both $B F$ and $B G P$ were motivated by regulatory interventions in a bank, such as replacing management or making other significant changes in the bank's administration. They argued that some of these changes could increase a bank's value. While not explicitly motivated by contingent capital, the cases they studied are mathematically identical to a regulator deciding whether to convert debt to equity based on the market price.
} 
Consider first a value-increasing scenario. In this case the informational problem is similar to that in the fixed-price regime, except that the regulator is left with the problem of inferring the desirability of conversion from an observed market price. For example, suppose $\theta$ $=\$ 3.50$. In this case conversion is socially warranted, and, if it occurred, would leave incumbent equity holders with an asset worth $\theta+\omega=\$ 5.50$. The traders could trade the asset at $\$ 5.50$ under the assumption of a conversion, but what if $\theta=\$ 5.50$ ? In that case conversion is not warranted, but the price would also be $\$ 5.50$. What should the regulator infer about the fundamental if he sees that price? What should traders assume the regulator will do? This situation can be understood by again referring to Figure 1. At prices below $\$ 3.00$ the regulator can unambiguously infer that conversion is desirable, since it must be the case that $\theta$ $<\$ 3.00$ no matter what traders assume that the regulator will do. Similarly, at prices of $\$ 7.00$ or above the regulator can conclude that conversion is not desirable, since it must be the case that $\theta \geq \$ 5.00$. However, for prices in the [\$3.00, \$7.00) range, it is not clear what the regulator should infer about the fundamental and what traders should infer about what the regulator will do. Clearly, the price schedule suggested by the bold lines in Figure 1 cannot be an equilibrium. Furthermore, it can be shown that no price schedule exists that is an equilibrium. ${ }^{15}$

In contrast, when conversion is value decreasing there is a unique equilibrium. The value decreasing conversion preserves the monotonic relationship between fundamentals and prices, so the regulator can determine the fundamental from the price. The solid line in Figure 2 shows the equilibrium price function. It is characterized by a monotonically increasing line that jumps discontinuously at $\theta=\$ 5.00$, where the price jumps from $\$ 3.00$ to $\$ 5.00$. Although the line yields a unique price for each value, notice that no prices in the $\$ 3.00$ to $\$ 5.00$ range will be observed.

It can be verified that the equilibrium illustrated in Figure 2 is unique. To see this, first observe that the price function cannot be non-monotonic for the same reason identified in footnote 15. Second, observe that no other monotonic price function can be an equilibrium. With a monotonic price function, the regulator can determine whether the fundamental is above or

\footnotetext{
${ }^{15}$ The formal proof of nonexistence is simple. No price schedule with $P\left(\theta_{1}\right)=P\left(\theta_{2}\right)$, for $\theta_{1} \neq \theta_{2}$ can be an equilibrium because the regulator would convert with the same probability for these two states, which means their prices would differ. No price schedule with a unique price for each value of $\theta$ can be an equilibrium either because then the regulator could figure out the fundamental from the price and would convert only for $\theta<\hat{\theta}$. But then, there would not be a unique price for each value of $\theta$, which is a contradiction.
} 
below $\hat{\theta}$ and so will only convert when $\theta<\hat{\theta}$. But this behavior is only consistent with the price function in Figure 2.

In the value-decreasing case, the uniqueness of the equilibrium contrasts with the multiple equilibria of the fixed-price trigger. The ability of the regulator to choose whether to convert is what eliminates the other equilibria. For example, if $\theta=\$ 6.00$ and traders assume that there would be conversion then they would price the security under the fixed-price trigger at $\$ 4.00$. But then the regulator would know that $\theta=\$ 6.00$ because if $\theta=\$ 4.00$ then the price would be $\$ 2.00$. Consequently, the regulator would not convert and the trader's expectations would be incorrect. In contrast, under the fixed-price trigger if the traders assume there will be conversion at $\theta=\$ 6.00$, then they price the security at $\$ 4.00$ and the trigger mechanically carries out the conversion, ignoring the information about $\theta$ conveyed by the price.

2.3 A Prediction-Market Regime. A variant of the regulator regime that provides regulators with additional information sufficient to allow them to distinguish between two fundamentals that deliver the same price would resolve the equilibrium non-existence problem in the case of a value-increasing conversion. In their environment BGP prove that a "prediction market” that elicits the market's assessment of the likelihood of a conversion is a mechanism that produces such information. Empirically, the accuracy of prediction markets has been extensively documented. In over a decade of experience, prices in political stock markets have consistently predicted ultimate vote counts more accurately than polls (see, e.g., Berg, Forsythe, Nelson, and Rietz, 2008), and prediction markets are now increasingly used in business and policy contexts to assess event probabilities. ${ }^{16}$

The potential information-correcting role of a prediction market is easily understood intuitively. Consider again the parameters in the Regulator regime, but suppose that in addition to equity, traders buy and sell “conversion likelihood tickets," which take on a value of \$1.00 if the regulator elects to make a conversion and $\$ 0.00$ otherwise. The ticket price, which is between $\$ 0.00$ and \$1.00, reflects traders’ collective expectation of a conversion. Ticket prices close to $\$ 1.00$ imply that traders collectively regard conversion to be very likely. In a value-increasing

\footnotetext{
${ }^{16}$ In discussing an internal prediction market conducted by Google, Cowgill, Wolfers, and Zietwitz (2009) observe that a host of firms have begun using prediction markets to predict events pertinent to the firm. In addition to Google, examples include Abbott Labs, Arcelor Mittal, Best Buy, Chrysler, Corning, Electronic Arts, Eli Lilly, Frito Lay, General Electric, Hewlett Packard, Intel, InterContinental Hotels, Masterfoods, Microsoft, Motorola, Nokia, Pfizer, Qualcomm, Siemens, and TNT.
} 
conversion scenario, for example, a ticket price of $\$ 0.95$ allows the regulator to conclude that a price of, say, \$6.00 incorporates fully the value of the expected conversion (implying that the underlying market fundamental is close to $\$ 4.00$ ). Similarly, a ticket price of $\$ 0.05$, would allow the regulator to conclude that the same $\$ 6.00$ equity price reflects the asset's underlying fundamental value, absent a conversion-induced adjustment.

As discussed above, in the case of a value-decreasing conversion, a unique equilibrium price exists for every fundamental realization. Nevertheless, to the extent conversion errors occur in markets with value-decreasing actions, a prediction market may also improve informational efficiency because it provides the regulator with information regarding the appropriate interpretation of prices in the $[\$ 3.00, \$ 5.00)$ range.

Table 1 summarizes reference predictions for the six environments discussed above. As seen in the top two rows of the table, in the Fixed-Trigger regime, no equilibrium exists for market fundamentals between $\$ 3.00$ and $\$ 4.99$ when the conversion increases value. When the conversion reduces value multiple equilibria exist for market fundamentals between $\$ 5.00$ and \$6.99. Moving down the table, the Regulator regime extends the equilibrium nonexistence range to [\$3.00, \$7.00) when conversions increase value. However, when conversions decrease value, the Regulator regime yields no predicted problems of equilibrium multiplicity or nonexistence. Finally, as shown at the bottom Table 1 the addition of a prediction market eliminates all predicted problems of equilibrium nonexistence that arise in the Regulator regime.

The purpose of the experiment described in the following sections is to evaluate the behavioral relevance of these predictions. Importantly, we are primarily concerned with the links between the predicted equilibrium properties of markets and market performance measures such as pricing precision, allocative efficiency and the incidence of conversion errors. The expected links are straightforward: Relative to a baseline case with a unique equilibrium, the existence of multiple equilibria should create coordination problems which will cause price bias (relative to the efficient equilibrium price) and/or price dispersion. In turn this informational inefficiency may prompt allocative (trading) inefficiencies as price uncertainty interferes with the flow of units from low to high value traders. In the case of equilibrium nonexistence, theory is silent as to expected outcomes, so behavioral beliefs within and across markets could be just about anything. We expect this heterogeneity of beliefs will yield diverse expectations that also 
adversely affect market performance in ways that parallel our expectations in the case of multiple equilibria.

\section{Experimental Design and Procedures.}

3.1 Background. A relatively large experimental literature examines asset markets performance. The branch of this literature most pertinent to the present investigation examines the capacity of traders to aggregate disparate information regarding a valued asset in a repeated single-period design. ${ }^{17}$ Plott and Sunder (1988) evaluate 12-trader markets in which traders are uniformly endowed with a portfolio consisting of cash and a number of homogenous assets, the value of which is determined at the end of the period by its fundamental. Traders are divided into three groups, each of which is told one of the three values that the asset will not take. Traders then buy and sell assets in a standard open book double auction. Plott and Sunder find some evidence that trading does allow sellers to identify the underlying value. Nevertheless, information aggregation is often incomplete in the sense that prices often deviate substantially from the underlying fundamental. Using a similar design, Forsythe and Lundholm (1990) find that experience appears to improve information aggregation. More recently Hanson et al. (2006) and Oprea et al. (2007) examine variants of the Plott and Sunder design with the modification that a subset of traders were motivated to bias market prices in a particular direction. Results in both papers indicate that even a sizable number of manipulators find altering prices in a desired direction difficult. Nevertheless, as in the related research, prices often failed to reflect underlying value.

Our research questions require some substantial deviations from these informationaggregation designs. We are interested in examining a market where the fundamental value is unknown to the monitor and revealed only through trading. Further, to generate trade we must induce some heterogeneity in asset values. At the same time, however, we seek a baseline context where traders aggregate information sufficiently to make market prices reflect

\footnotetext{
${ }^{17}$ Another branch of the experimental asset market literature, initiated by Smith, Suchanek, and Williams (1988), considers the capacity of traders to track the underling fundamental value of a relatively long-lived asset that yields stochastic returns. Results indicate a persistent propensity for speculative pricing bubbles. This result appears resilient to a variety of conditions, including brokerage fees, short selling or subjects drawn from subpopulations of corporate managers or professional stock traders (see, e.g., King et al., 1993, Lei, Noussair, and Plott, 2001). Common experience with the trading institution appears to minimize the propensity toward speculative pricing. However, recent research by Hussam et al. (2008) indicates that other factors, such as dividend uncertainty and a capacity to sell short can reignite bubbles even with very experienced traders.
} 
reasonably well the underlying fundamental. Satisfying these design constraints requires us to deviate somewhat from the theoretical environments used by $B F, B G P$ and $S W$. Although our design does not precisely implement any of these environments, the theory does provide useful insight into the interrelationships between various conversion mechanisms and market prices.

\subsection{Experiment Design. The experiment consists of a BASE condition and three conversion rule} treatments that correspond to the three regimes described above: a Fixed-Trigger regime where equity prices below a publicly announced price level automatically trigger a conversion, a Regulator regime, where a price-informed monitor makes conversion decisions, and a Prediction Market regime, where the results of a prediction market supplement the price information provided to monitors. In each regime we conduct treatments with value-increasing conversions and value-decreasing conversions. All treatments are extensions of a BASE condition, which we explain first.

3.2.1 BASE Condition. The BASE condition consists of 10 traders and 3 monitors. ${ }^{18}$ In each period traders are endowed with two units of an asset, and a working capital loan of \$16 lab. ${ }^{19}$ Also, an underlying fundamental asset value $\theta_{1}$ is drawn from a uniform distribution $U[\$ 2.00, \$ 8.00]$. To motivate trade, we introduce some value heterogeneity across traders. Six of the traders value the asset at $\theta_{1}$ and the remaining four traders value the asset at 60 cents less, i.e., their valuation is $\theta_{2}=\theta_{1}-60 \leftarrow$. The value distribution, the relation between high and low values, and the aggregate number of high- and low-value traders are read aloud to traders in the instructions, so are common knowledge. Traders are also told their own valuation, but do not know if their own valuation is the low or high one.

In this market design, trade should move assets from the low- to the high-value traders and in the process reveal $\theta_{1}$. Aggregating value realizations, as shown in Figure 3, reveals a substantial excess demand for high-value units, providing considerable incentive for prices to rise to the "market" fundamental $\theta_{1}$.

\footnotetext{
${ }^{18}$ This is true of all BASE condition periods except those that preceded the Fixed Trigger treatments. No monitors were needed in the Fixed Trigger treatments, so the BASE condition periods that preceded these treatments consisted only of 10 traders who exchange asset units each period.

${ }^{19}$ Lab currency is converted to U.S. cash at the end of the session. To avoid repeating the word 'lab,' in the text currency units are reported simply as 'dollars.'
} 
The market is organized as a standard, open book double auction (similar to the rules used on the NYSE), and traders may buy and sell asset units as they see fit. ${ }^{20}$ Trading periods last 110 seconds. At the end of each period, payoffs for each trader of type $k$ are determined as the sum of earnings from the sale of units and the fundamental value of all units owned at the end of the period, or

$$
\text { Payoff }_{k}=-\sum_{i=1}^{n_{b}} p_{i}+\sum_{j=1}^{m_{s}} p_{j}+\theta_{k} \times\left(n_{b}-m_{s}+2\right),
$$

where $n_{b}$ units are bought at prices $p_{i}, i=\left\{1, \ldots, n_{b}\right\}$ and $m_{s}$ units are sold at prices $p_{j}, j=\left\{1, \ldots, m_{s}\right\}$ and $\theta_{k}$ is the fundamental value of units owned by the trader at the end of the period. The working capital balance nets out of equation (1), as traders also repay the balance at the end of each period.

Finally, at the close of each period monitors are shown the median transaction price and then asked to guess $\theta_{1}$. Monitors make decisions simultaneously, and once all decisions are complete the actual $\theta_{1}$ is revealed. Monitors earn $\$ 3$ if their guess is within 20屯 of $\theta_{1}$, $\$ 1$ if their guess is within 50\& of $\theta_{1}$, and zero otherwise. Absent the possibility of conversion, markets in BASE periods should aggregate information effectively. Operationally, this would mean that the markets are informationally efficient in the sense that the deviation between median prices and the market fundamental $\theta_{1}$ is small, as well as allocatively efficient, in the sense that a high percentage of total available gains are extracted from exchange. ${ }^{21}$

3.2.2. Fixed-Trigger Regime. To evaluate the performance of markets operating under a potential conversion scenario, we use $\$ 5.00$ as the threshold for a socially efficient conversion. This threshold is arbitrary, but has the advantage of being in the middle of our range of fundamentals, so we can examine experiments with values of the fundamental that are both above and below the threshold and near and far from it.

\footnotetext{
${ }^{20}$ Organizing the market as a simultaneous move institution, such as a call market, would be procedurally simpler. Overall, call markets perform quite favorably relative to double auctions (see, e.g., Cason and Friedman, 2008, and Kagel, 2004). However, a number of experimental studies indicate that simultaneous move institutions like the call market are susceptible to information cascades (Anderson and Holt, 1997) and the winner's curse (Kagel and Levin, 1986), and are thus less desirable as information aggregation mechanisms. See, e.g., Plott (2001), or, for information aggregation problems in a context that is in some respects related to the one examined here, Duffy and Fisher (2005).

${ }^{21}$ We calculate allocative efficiency as the percentage of units held by high-value traders at the end of each trading period. The maximum gain from efficient portfolio reallocation is $\$ 4.80$ lab: $60 \$$ each from the movement of the eight units held by "low-value" traders (with values of $\theta_{2}$ ) to "high-value" traders (with value of $\theta_{1}$ ).
} 
Asset holders realize an adjustment to asset values whenever a conversion is triggered. For markets operating under a fixed conversion trigger, traders were informed that a conversion would occur at the close of trade in a period if the median contract price is less than $\$ 5$. In the value-increasing scenario the value of assets increases by $\$ 2.00$ in the case of a conversion, so for high-value traders the value is $\theta_{1}+\$ 2.00$ and for low-value traders it is $\theta_{1}-\$ 0.60+\$ 2.00$. Sessions in the value-decreasing scenario are structured in exactly the same way except that a conversion reduces the value of an asset by $\$ 2.00$.

3.2.3 The Regulator Reqime. Conditions for the Regulator treatments duplicate those for the Fixed-Trigger treatments with the following difference: Rather than using median transaction price below $\$ 5.00$ as a conversion trigger, monitors observe the median transaction price after the close of trade, and then make a conversion decision under the condition that conversions are desirable if the market fundamental $\theta_{1}$ is less than $\$ 5$. Monitors earn $\$ 10$ for a correct conversion decision. This $\$ 10$ payment is in addition to the up to $\$ 3$ in earnings monitors realize for accurately assessing the underlying market fundamental (as they did in the BASE condition periods). The relatively large payment for correct conversion decisions reflects incentives for regulators in natural contexts, where regulatory intervention can have a high fixed cost and can be costly when implemented inappropriately. Furthermore, it gives the regulators an incentive to make the same decision as would occur under a fixed-trigger when the fundamental was observed. $^{22}$

After all decisions are complete, $\theta_{1}$ is revealed to the monitors, and the action of one of the three monitors is selected at random and implemented. As with the Fixed-Trigger regime, the value of assets increases by $\$ 2.00$ in the case of a value-increasing conversion and falls by $\$ 2.00$ in the case of a value-decreasing conversion.

\subsubsection{Prediction Market Regime. To evaluate the capacity of prediction markets to correct} any informational inefficiencies observed in the Regulator regime, we conducted a pair of treatments that parallel the Regulator treatments, except that at the beginning of each period each trader is endowed with a conversion likelihood ticket ('ticket'). Tickets are worth $\$ 1$ (lab) at the end of the period if the monitor decides to convert and $\$ 0$ otherwise. Prior to the onset of equity trading, traders are given the opportunity to buy and sell tickets by submitting both a maximum

\footnotetext{
${ }^{22}$ To keep monitors from 'hedging' conversion decisions with their fundamental value guesses, we imposed a consistency condition on conversion decisions and fundamental value guesses: Specifically, a monitor could elect to convert if and only if she guessed that market fundamental was below $\$ 5.00$.
} 
bid to purchase a second ticket and a minimum offer to sell their ticket. ${ }^{23}$ A call market is used to determine a market ticket price as well as the number of tickets that change hands: Bids are ranked from highest to lowest, offers are ranked from lowest to highest, and a crossing is made. The market price of a ticket is determined as half the distance between last “inside” bid and offer. ${ }^{24}$ All "inside” units exchange, with tickets passing from sellers to buyers at the market price. Following the ticket exchange, trading proceeds as in the initial Regulator treatment, except that the market price of a ticket is displayed to all traders and monitors.

3.3 Experiment Procedures. At the outset of each session participants were randomly seated at visually isolated PCs. An experiment administrator then read aloud a common set of instructions, which explained incentives for traders and for monitors in the BASE condition, as well as how to make decisions on the computer interface used in the experiment. ${ }^{25}$ The experiment was programmed and conducted with the software z-Tree (Fischbacher, 2007). To facilitate understanding, screen shots were projected onto a wall at the front of the lab. Following the instructions, participants completed a short quiz of understanding, which the experiment administrator reviewed publicly. Finally, participants completed a practice period for which they were not paid. At any time during the instructions, quiz, and practice period, participants were encouraged to ask questions by raising their hands. Questions were answered privately. Following completion of the practice period, the session commenced.

After five periods in the BASE condition the session was paused and additional instructions were distributed for an additional segment. An experiment administrator then read aloud these instructions and administered another short quiz of understanding. An identical protocol was followed for subsequent segments. Following the conclusion of the last segment the experiment ended, and participants were privately paid and dismissed from the lab.

In total, the experiment consisted of a series of 34 sessions divided into six treatments: value increasing and value decreasing conversion variants of the Fixed-Trigger, Regulator and Prediction Market regimes described above. Table 2 summarizes the experiment design. In the Fixed-Trigger sessions, the remainder of the session following the initial BASE condition periods

\footnotetext{
${ }^{23}$ Bids and offers are submitted under the conditions that the maximum offer cannot exceed \$1 (since that is the ticket's maximum value), and that each trader's offer must exceed his bid (so that the trader does not sell to himself).

${ }^{24}$ That is, the last ranked bid and offer pair where the bid is no greater than the offer. In the case that no offer exceeds a bid, the price is set as half the distance between the lowest offer and the highest bid.

${ }^{25}$ Instructions are available in an unpublished appendix.
} 
was divided into two 10-period segments, one with a value-increasing conversion condition, and the other with a value-decreasing conversion condition. To control for possible order of sequence effects, we rotated the order of the value-increasing and value-decreasing segments across treatments. We conducted six Fixed Trigger sessions, generating six independent 'FT$V I C$ ' segments in the value-increasing conversion condition as well as six independent ' $F T$ $V D C$ ' segments in the value-decreasing conversion condition.

In the Regulator treatments, a single 15-period sequence followed the BASE condition periods. In eight 'REG-VIC' sequences monitors made conversion decisions under a value increasing conversion condition. In another eight ' $R E G$-VDC' sequences monitors made conversion decisions under a value-decreasing conversion condition. Finally, in the Prediction Market treatments, the five initial BASE condition periods were followed by two additional segments, five periods in a Regulator segment and then 10 periods in which a Prediction Market supplemented the Regulator regime. We conducted six 'PRED-VIC' sequences in the value increasing conversion condition as well as six 'PRED-VDC' sequences in the value decreasing conversion condition. ${ }^{26}$

In total, 424 undergraduate student volunteers participated in the experiment. Participants were upper-level math, science, engineering, and business students enrolled in courses at Virginia Commonwealth University in the spring semesters of 2010 and 2011. No one participated in more than one session. Lab earnings were converted to U.S. currency at \$12 lab $=\$ 1$ U.S. rate. Participant earnings for the 90-120 minute sessions ranged from $\$ 14$ to $\$ 32.25$ and averaged $\$ 23.25$ (inclusive of a $\$ 6$ appearance fee). ${ }^{27}$

\section{Experiment Results.}

\footnotetext{
${ }^{26}$ To facilitate the comparison of outcomes across treatments, a common set of fundamental realizations were used in the Fixed-Trigger and Prediction Market treatments. A slightly different set of value realizations was used in the longer Regulator sessions. Appendix A lists displays sequences of market fundamental realizations used in the experiment.

${ }^{27}$ A more general concern about financial market experiments regards the representativeness of the standard university undergraduate student subject pool as equity traders or regulators merits some consideration. Ultimately, this latter concern is also an empirical issue that could be resolved with experimentation. We do observe, however, in a variety of contexts researchers have investigated the effects of recruiting participants from the markets being studied. The behavior of these participants has typically not differed from that exhibited by more standard (and far less costly) student subject pools. In particular, speculative pricing bubbles persist in laboratory markets using subjects drawn from subpopulations of corporate managers, independent small business persons and professional stock traders (See King et. al., 1993, Lei et. al. 2001).
} 
Figures 4 and 5 plot three market performance measures for the Fixed-Trigger and Regulator regimes relative to the BASE condition -- mean price deviations, allocative efficiencies and conversion error rates. In each bar graph observations are clustered into six ranges of fundamental realizations; partitions of the \$3.00-\$4.99 and \$5.00-\$6.99 segments where theoretical results predict treatment effects, as well as the remaining $<\$ 3.00$ and $\geq \$ 7.00$ segments. Our partition of the \$3.00-\$4.99 and \$5.00-\$6.99 segments separates out the ranges $60 \$$ above and below the $\$ 5.00$ efficient conversion limit from the remainder of the segments (e.g., \$3.00-\$4.49, \$4.40-\$4.99 and \$5.00-\$5.59, \$5.60-\$6.99). Although the proximity of a market fundamental realization to $\$ 5.00$ is not pertinent in the models by $B F, B G P$ or $S W$ (all of which use a rational expectations framework), it may well affect market performance in a more fully specified market context like that examined here, that includes the value heterogeneity necessary to induce trade. ${ }^{28}$

Consider first results for the BASE condition periods, shown as white bars in Figure 4. Mean price deviations for the BASE condition at about -20థ in each segment are uniformly negative and small, indicating that prices are between $\theta_{1}$ and $\theta_{2}$ and tend to be closer to market fundamental $\theta_{1}{ }^{29}$ While imperfect, this level of informational efficiency is fairly impressive relative to other information aggregation experiments (e.g., Plott and Sunder, 1988, Forsythe and

\footnotetext{
${ }^{28}$ In the present context, fundamental realizations within $60 \varnothing$ of $\$ 5.00$ imply that some traders cannot determine ex ante the position of the market fundamental relative to the efficient conversion cutoff. A trader seeing a fundamental realization of $\$ 4.80$ in a period, for example, will find herself either in a situation where the market fundamental is $\$ 4.80$, in which case a conversion is warranted, or in a situation where the market fundamental is $\$ 5.40$, in which case a conversion is not warranted. Traders facing such uncertainty must rely on information gained from trading activity (e.g., bids, offers and contracts) to draw an inference about the market fundamental. Importantly, only a subset of traders cannot determine the position of the market fundamental relative to the $\$ 5.00$ efficient conversion cutoff. Remaining traders can infer the fundamental. In the case that some traders realize a fundamental of $\$ 4.80$, for example, the remaining traders will have fundamental realizations of $\$ 4.20$ or $\$ 5.40$, either of which allows a definitive ex ante assessment of the market fundamental. If traders initially restrict bids and offers to what they know about the market fundamental, (e.g., the $\$ 4.20$ and $\$ 5.40$ traders initially submit bids and offers) we conjecture that actions of the informed traders may allow the uninformed to draw a correct inference. Nevertheless, verifying such a conjecture is well beyond the scope of this paper, as no well-accepted reference model for characterizing the price-convergence process in the double auction trading institution used in our markets exists.

${ }_{29}$ In general, average deviations from a reference price would illustrate only price bias, or a directional deviation of prices from a reference prediction and would disguise price imprecision when prices are symmetrically distributed about the predicted price because positive and negative price deviations cancel each other out. In the present experiment, however, price deviations in each treatment overwhelmingly occur in a particular direction, making absolute and average deviations similar in magnitude and different largely only in sign. Tables A4 and A5 in the Appendix summarize the relationship between absolute and average price deviations observed here. In 33 of 42 treatment/fundamental segment cells, average and absolute average prices are within $5 \mathbb{\$}$ of each other, and in 26 of

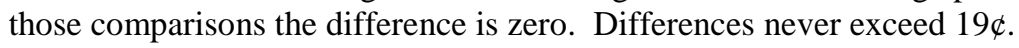


Lundholm, 1990, Hansen et al., 2006, or Oprea et al., 2007). ${ }^{30}$ Similarly, while varying slightly across segments, allocative efficiencies in the BASE condition are uniformly high, averaging about 95\%, indicating that in the BASE condition nearly all asset units are allocated to highvalue traders. The high allocative efficiencies in our BASE condition periods are quite typical of laboratory markets conducted in the robustly competitive double-action trading institution.

A series of simple regressions quantifies these results. For informational and allocative efficiency we regress absolute mean price deviations as well as allocative efficiencies against a series of indicator variables delineating fundamental realization segments. ${ }^{31}$ Then for each segment we add interaction terms to capture the incremental effects of each regime (FT or REG) in each conversion condition (VIC or VDC). All regressions cluster data by markets and use a robust (White “sandwich”) estimator to control for possible unspecified autocorrelation or heteroskedasticity. Also, we suppress the regression constant to report mean values for each $B A S E$ condition segment, rather than deviations from one of the segments. Wald tests are subsequently used to assess differences across BASE condition ranges.

Regression results for the BASE condition periods, shown in the upper panel of Table 3 yield observations parallel to those just made. Looking first at mean absolute price deviations, observe in column (1) that absolute mean price deviations vary from $14 \mathbb{C}$ in the $<\$ 3.00$ fundamental range, to $28 \leftarrow$ in the $>\$ 7.00$ range. Although differences are quantitatively rather small, some significant differences do exist. The $14 \$$ deviation for the $<\$ 3.00$ range, for example, falls significantly below the $21 \$$ deviation for the $\$ 4.40$ - $\$ 4.99$ range, and the $28 \$$ deviation for the upper $\geq \$ 7.00$ segment significantly exceeds the same $21 \mathbb{\leftarrow}$ deviation, both at $p<0.05$. Similarly, as seen in column (2), mean allocative efficiencies vary between 93\% and 98\% across segments with only the $98 \%$ efficiencies for the $\$ 5.00-\$ 5.59$ and \$3.00-\$4.39 segments differing significantly from $95 \%$ deviation for the $\$ 4.40-\$ 4.99$ range (at $p<0.05$ and $p<0.10$, respectively). In sum, we conclude that while imperfect, our BASE condition provides a reasonably informationally and allocatively efficient backdrop against which the incremental effects of the three conversion rules that are the primary focus of our investigation can be compared.

\footnotetext{
${ }^{30}$ Drawing an explicit standard of comparison across these different experiments is difficult. However, in each of the referenced experiments the authors regard information aggregation as "highly incomplete" and price variations are very large.

${ }^{31}$ In our regressions we estimate absolute rather than average price deviations to facilitate inter-treatment comparisons. Differences in average price deviations artificially inflate informational efficiency differences for comparisons across treatment/fundamental segment cells where price deviations have different signs.
} 
4.1.1 The Fixed-Trigger Regime. Results for the Fixed-Trigger treatments, also illustrated in Figure 4, reflect the behavioral consequences of equilibrium nonexistence and multiple equilibria established by SW. Looking first at the FT-VIC condition, shown as black bars, observe that for fundamental realizations below $\$ 5.00$ mean price deviations are again negative and much larger than in the BASE condition. The deviations steadily increase in the \$3.00-\$4.39 and \$4.40 - \$4.99 segments, since in these segments traders must also confront incentives to keep prices below $\$ 5.00$ to assure that conversion does in fact occur. For fundamental realizations above $\$ 5.00$ units trade close to the market fundamental and average deviations become very small, as uncertainty about an ex post conversion disappears.

Allocative (trading) efficiency in the FT-VIC treatment falls relative to the BASE condition in all ranges of market fundamentals, as traders adjust imperfectly to the possibility of a conversion when making bids and offers. Mean trading efficiency in the $\$ 4.40$ - $\$ 4.99$ range, at $73 \%$, is particularly low for markets conducted under double auction trading rules. Higher levels of trading efficiency are typical in such markets, even when conducted in very challenging environments. $^{32}$ Observe finally in the bottom panel of Figure 4 that as an added consequence of the low informational efficiencies in the \$4.40- \$4.99 range, conversion errors for the FT-VIC treatment occur frequently - in nearly $60 \%$ of the pertinent instances.

For the FT-VDC treatment, shown as gray bars in Figure 4, mean price deviations, while somewhat smaller in magnitude than in the FT-VIC treatment are still quite large when compared to the BASE treatment. For fundamental realizations below $\$ 5.00$ mean deviations are positive in sign, indicating that traders incompletely incorporate the value of what should be an anticipated $\$ 2.00$ conversion into contract prices. Larger negative deviations occur in the \$5.00-\$5.59 segment of fundamental realizations, a portion of the range where $S W$ predict that multiple equilibria exist, and where coordination on the inefficient equilibrium will prompt traders to incorporate the negative value of a socially unnecessary conversion into their prices. ${ }^{33}$ Despite

\footnotetext{
${ }^{32}$ For example, in a very demanding double auction design with inexperienced traders where each period supply and demand receive random shocks and where relative cost and value assignments are reshuffled among sellers and buyers, respectively, Cason and Friedman (1999) observe mean trading efficiencies of 88.4\%. In a similar eightseller design, also with inexperienced traders, Kagel (2004) observes average trading efficiencies of 95\%.

${ }^{33}$ To a large extent the comparatively small mean absolute price deviations in the FT-VDC treatments is a consequence of differing reference predictions. In the \$3.00-\$4.39 and \$4.40-\$4.99 segments that are problematic in the FT-VIC condition, price deviations are assessed relative to the (efficient) conversion-inclusive market price. In the \$5.00-\$5.59 and \$4.50-6.99 segments that are problematic for the FT-VDC treatment, price deviations are evaluated relative to the no-conversion prediction. Thus for example, $50 \varnothing$ upward adjustment relative to the no-
} 
the relatively high mean absolute price deviations in the \$5.00-\$5.59 segment, allocative efficiency remains comparatively high. Allocative efficiency drops more prominently for fundamental realizations below $\$ 5.00$, where the need for traders to incorporate the value of conversion into their fundamental realizations impedes the capacity of prices to channel equity units from low to high value traders. Nevertheless, for fundamentals in the $\$ 5.00-\$ 5.59$ range, the fixed trigger generates a very large number of socially undesirable conversions, as traders frequently coordinate on a low value equilibrium.

The lower panel of Table 3 quantitatively summarizes the incremental effects of the FT-VIC and FT-VDC treatments. Incremental effects for the FT-VIC treatment, shown in columns (1) (3) clearly reveal a problem in the $\$ 3.00$-\$4.39 and particularly in the $\$ 4.40-\$ 4.99$ segments: Mean absolute price deviations increase over the BASE condition by $86 \mathbb{\$}$ and 141థ, respectively, and allocative efficiencies falls by 24 and 23 percentage points. The incidence of conversion errors is most prominent in the $\$ 4.40$ - $\$ 4.99$ segment, occurring in 58\% of pertinent instances. ${ }^{34}$ Each of these deviations is significant at $p<0.05$.

Estimates for the FT-VDC treatment, summarized in columns (4) to (6) of Table 3 similarly support the conclusion that the multiplicity of equilibria for realizations above $\$ 5.00$ can importantly affects market performance. For the \$5.00-\$5.59 segment of fundamental realizations, mean absolute price deviations increase by $43 \phi$ over the BASE condition, and conversion errors occur in $67 \%$ of pertinent instances. Each of these deviations differs significantly from zero at $p<0.05$.

Thus, in sum, experimental results indicate that the problems of equilibrium nonexistence (in a value-increasing condition) and multiple equilibria (in a value-decreasing condition) associated with use of a fixed trigger can prominently undermine market performance. Market performance suffers particularly in the two 60๕ segments above and below the $\$ 5.00$ efficient conversion cutoff, suggesting that in this range the added difficulty of inferring the market fundamental from market prices importantly affects market performance.

conversion reference for a fundamental realization just below $\$ 5.00$ in the FT-VIC treatment is consistent with a $150 \notin$ absolute mean price deviation, while a $50 \notin$ downward adjustment in the FT-VDC treatment is consistent with a $50 \varnothing$ absolute mean price deviation.

${ }^{34}$ The conversion error rate regressions summarized in the columns (3) and (6) of Table 3 are similar to the mean absolute price deviation and trading efficiency estimates, except that BASE periods (where no conversion decisions occurs) are omitted. The incremental effect of conversion errors are evaluated relative to the $>\$ 7.00$ range of the FT-VIC treatment where no conversion errors occurred. Conversion error rates are estimated similarly for the Regulator and Prediction Market treatments. 
4.1.2. The Regulator Regime. Figure 5 summarizes outcomes of the Regulator treatment relative to the BASE condition. Shown as black bars, the REG-VIC markets generate informational efficiency losses similar to those observed in the FT-VIC counterpart. For fundamentals below $\$ 5.00$, mean price deviations are negative and substantially larger than in the BASE condition, with deviations becoming particularly large when fundamentals are in the segment just below $\$ 5.00$. In the segments above $\$ 5.00$ mean price deviations are uniformly quite small, as units trade at prices close to their ex ante fundamental value. Allocative efficiency also suffers relative to the BASE condition in all REG-VIC segments, but with particularly large losses in the $\$ 3.00-\$ 4.39, \$ 4.40-\$ 4.99$ and $\$ 5.00-\$ 5.59$ ranges. Finally, conversion errors are frequent and, unlike in the fixed trigger treatment, occur in every segment but the highest one. Notice in particular that in addition to a high frequency of errors in the $\$ 4.40$-\$4.99 segment, the modal conversion error rate occurs in the \$5.00-\$5.59 segment, as regulators, observing median prices close to but above $\$ 5.00$, often errantly believe that a conversion is warranted. The dispersion of conversion errors both above and below $\$ 5.00$ is consistent with $F B$ and $B G P$ who predict that in the REG-VIC treatment the range of fundamental realizations where no equilibrium exists extends from \$3 to \$6.99.

Results for the REG-VDC regime are shown as gray bars in Figure 5. The gray bars suggest that the presence of a discretionary monitor can adversely impact market performance even when the Walrasian model of BGP predicts a unique equilibrium. Notice first that relative to the BASE condition, $R E G-V D C$ markets are both informationally and allocatively inefficient. Except for

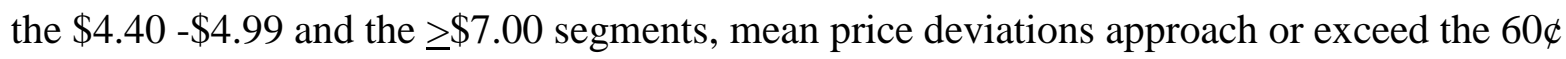
difference between $\theta_{2}$ and $\theta_{1}$. Similarly, in each segment mean allocative efficiencies fall below levels observed in the BASE condition. Furthermore, a large number of conversion errors occur in the REG-VDC treatment and these are concentrated in the \$5.00-\$5.59 segment.

The high incidence of conversion errors in the \$5.00-\$5.59 range parallels results for the FTVDC treatment. Contrary to equilibrium predictions the presence of an active regulator fails to eliminate prices in the ambiguous \$3.00 - \$4.99 range. Monitors, in response, apparently often adopt a simple cutoff strategy, similar to the fixed price rule in the FT-VDC treatment, where they do not intervene when the median price is below the cutoff and intervene when the market price exceeds it. As a result, conversion errors occur frequently in the $R E G-V D C$ treatment. 
Table 4 summarizes quantitatively the incremental effects of the REG-VIC and REG-VDC treatments. Informational efficiency results for the REG-VIC treatment, shown in column (1) reveal large losses in the two segments immediately below $\$ 5.00$ : For the $\$ 3.00-\$ 4.39$ segment the mean absolute price deviation increases by $93 \$$ relative to the BASE condition and for the \$4.40-\$4.99 segment price deviations increase by $130 \$$ over the BASE condition. Both deviations are significant at $p<0.05$. Allocative efficiency suffers generally relative to the BASE condition, with negative deviations significant at $\mathrm{p}<0.05$ in every segment but the $\geq \$ 7.00$ segment. Conversion error rates for the $R E G$-VIC treatment are similarly dispersed, with a significant incidence of errors in every segment but the upper $\geq \$ 7.00$ segment, and with particularly high levels of conversion errors in the two segments closest to $\$ 5$ : Conversion errors occur in $34 \%$ of instances in the $\$ 4.40-\$ 4.99$ segment and in $50 \%$ of instances in the $\$ 5.00-\$ 5.59$ segment.

Results for the REG-VDC treatment, summarized in columns (4) - (6) also exhibit informational and allocative efficiency losses relative to the BASE condition over a dispersed range of fundamental realizations. Using a $p<0.05$ level of significance, mean absolute price deviations differ significantly from BASE condition levels for each REG-VDC segment. Most importantly, in the \$5.00-\$5.99 range of fundamental realizations conversion errors occur in $45 \%$ of pertinent instances.

In summary then, for the Regulator regime, we find informational and allocative inefficiencies both above and below the $\$ 5.00$ conversion cutoff, in the case of a valueincreasing conversion, as predicted by $B G P$ and $B F$. As a consequence, conversion errors occur with frequency, particularly in the $60 \$$ segments above and below $\$ 5.00$. We also observe informational and allocative inefficiencies in the case of a value-decreasing conversion, which are not predicted in BGP. Moreover, in the case of value-decreasing conversions, monitors frequently make errant conversion decisions in the $\$ 5.00$-\$5.59 range of fundamental realizations.

4.2. Across-Treatment Comparisons. To some extent the informational and allocative inefficiencies of the fixed trigger and regulator-based mechanisms have a common explanation: uncertainty regarding the likelihood of a conversion ex post increases perceived value heterogeneity among traders. This value heterogeneity undermines both the potentially informative role of prices as well as the capacity of price signals to channel units from low to high value traders. 
Nevertheless, the treatments are not identical and may differ for both procedural and theoretical reasons. For example, despite theoretical problems of equilibrium nonexistence, or multiple equilibria, a fixed trigger rule offers possibly important advantages of clarity in implementation which may improve performance relative to other regimes. Furthermore, adding a prediction market to the Regulator regime resolves the theoretical problems in the Regulator regime, so may yield improved performance. This subsection considers the relative performance of the Fixed-Trigger and Regulator regimes as well as the potential ameliorative effects of a prediction market.

\subsubsection{Comparing Fixed-Trigger and Regulator Regimes. The bar graphs shown in} Figures 6 and 7 plot mean price deviations and conversion error rates for each regime in the value-increasing and value-decreasing conditions, respectively. Looking first at results for the value-increasing condition in Figure 6, notice that the pattern of mean price deviations in the FTVIC treatment (the white bars) and REG-VIC treatment (the black bars) are nearly identical. For the segments above $\$ 5.00$, mean prices uniformly track underlying fundamentals quite closely. Below $\$ 5.00$, however, mean price deviations fall progressively further below from the underlying value as prices approach the $\$ 5.00$ efficient conversion limit. Despite the similarity in the pattern of price performances, the FT-VIC and REG-VIC treatments generate distinctly different patterns of conversion errors, as is seen in the bottom panel of the Figure. In the FTVIC treatment, conversion errors are largely confined to the \$4.40-\$4.99 range of fundamental realizations. In contrast in the REG-VIC treatment conversion errors are considerably more dispersed, and occur frequently both above and below the $\$ 5.00$ efficient conversion limit. Looking at results of the value-decreasing condition, shown in Figure 7, notice that the elimination of multiple equilibria associated with replacing the fixed trigger rule with a regulator does nothing to improve informational efficiency. To the contrary, mean price deviations are slightly but consistently higher in the REG-VDC treatment than in the FT-VDC treatment. Similarly, the Regulator treatment does not importantly reduce the incidence of conversion errors. Although the mean conversion error rate in the \$5.00-\$5.59 segment is higher in the FT$V D C$ treatment than in the $R E G-V D C$ treatment, the incidence of conversion errors is more dispersed in the REG-VDC treatment, with errors occurring also in both the $\$ 4.40-\$ 4.99$ and \$5.60-\$6.99 segments. 
To formalize these observations we ran a series of regressions similar to those reported in Tables 3 and 4 except that we use the Fixed-Trigger treatment as the reference condition and estimate for each segment of fundamental realizations the incremental effects of the Regulator treatment. Regression results appear in Table 5. Looking at the estimates for the valueincreasing condition, summarized in columns (1)-(3), notice that the patterns of absolute mean price deviations and allocative efficiencies are very similar across the treatments. Mean absolute price deviations never differ significantly across treatments, and allocative efficiencies differ only once, in the $\$ 5.00$ - \$5.59 segment where allocative efficiency is 11 percentage points lower in the Regulator treatment. The primary difference between the two treatments regards the incidence of conversion errors. As seen in column (3), the incidence of conversion errors in the Regulator treatment in the \$4.40-\$4.99 segment falls by a large (albeit insignificant) 24 percentage points, but then increases by 42 percentage points in the $\$ 5.00-\$ 5.59$ segment and by 12 percentage points in the $\$ 5.60-\$ 7.00$ segments (with both differences significant at $p<0.05$ ).

For the value-decreasing conversion condition, absolute mean price deviations significantly increase for the Regulator treatment relative to the Fixed-Trigger treatment in the \$3.00-\$4.39 segment (at $p<0.10$ ) and in the \$4.40-\$4.99 segment (at $p<0.05$ ). Although the incidence of conversion errors in the Regulator regime falls in the \$5.00-\$5.59 segment by a large but insignificant 21 percentage points, conversion errors become more dispersed in the Regulator regime, occurring in at least 7\% of instances in the \$4.40-\$4.99 and \$5.60-\$6.99 segments (both of these differences are significant at $p<0.10$ ).

On the basis of these observations, we conclude that the addition of a regulator does not improve performance relative to a fixed price trigger. To the contrary, the reverse appears to be true. Informational efficiency in the Regulator regime appears to suffer somewhat in the case of a value-decreasing conversion. Further, in the value-increasing conversion condition the FixedTrigger regime generates fewer conversion errors, and in both the value-increasing and valuedecreasing conditions, the Fixed-Trigger treatment appears to concentrate errors into a more tightly focused range of fundamentals.

4.2.2. The Effects of a Prediction Market on the Regulator Regime. The light gray bars in Figures 6 and 7 illustrate mean price deviations and conversion error rates for the Prediction Market regime. A comparison of Prediction Market outcomes with Regulator outcomes (black bars) suggests that the addition of a prediction market substantially improves informational 
efficiency for fundamental realizations below $\$ 5$. As seen in the upper panel of Figure 6, in the case of a value-increasing conversion, for each range of fundamental realizations below \$5 mean price deviations for the PRED-VIC treatment are on the order of half the size of their REG-VIC counterpart. Similarly, as shown in the upper panel of Figure 7, in the case of value-decreasing conversions mean price deviations fall noticeably in the $<\$ 3.00$ and $\$ 3.00-\$ 4.39$ segments.

Nevertheless, this improvement in informational efficiency fails to eliminate conversion errors. As shown in the bottom panel of Figure 6, while the prediction market does reduce the range of fundamentals for which conversion errors occur, it does not affect the incidence of conversion errors in the $\$ 5.00$ - \$5.59 fundamental range that generated the modal value of conversion errors in the REG-VIC treatment. Similarly, as seen in Figure 7, in the case of a value-decreasing conversion, the prediction market does not importantly affect the incidence of conversion errors in any range relative to the Regulator regime.

Table 6, which reports results of a series of regressions similar to those reported in Table 5, evaluates the incremental effects of the Prediction Market relative to the Regulator regime, and provides quantitative support for the above observations. As shown in columns (1) and (4) the addition of a prediction market improves informational efficiency for fundamental realizations below the $\$ 5.00$ efficiency conversion cutoff. In the case of a value-increasing conversion, mean absolute price deviations falls significantly for all segments below $\$ 5.00$ at

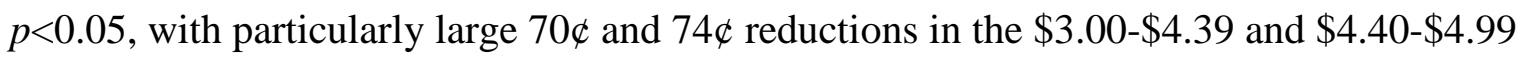
ranges, respectively. In the case of a value-decreasing conversion, mean absolute price deviations fall by $37 \mathbb{\$}$ in the $<\$ 3.00$ segment (significant at $p<0.10$ ) and by $41 \mathbb{4}$ in the $\$ 3.00$ $\$ 4.39$ segment (significant at $p<0.05$ ). Further, in the value-increasing conversion condition, the prediction market significantly reduces the incidence of conversion errors in four of the six fundamental realization segments $(<\$ 3.00$ at $p<0.10$ and $\$ 3.00-\$ 4.39, \$ 4.40-\$ 4.99$ and $\$ 5.60$ $\$ 7.00$ at $p<0.05)$. Nevertheless, in the $\$ 5.00-\$ 5.59$ range of fundamental realizations, the segment where conversion errors occur with the highest frequency in the Regulator treatment, the prediction market fails to affect the incidence of conversion errors. Similarly, in the case of a value-decreasing conversion, the prediction market fails to significantly affect the incidence of conversion error in any segment, and particularly in the \$5.00-\$5.59 segment where errors occur with the highest frequency in the Regulator regime. 
The listing of mean conversion likelihood ticket prices by market fundamental ranges in Table 6 provides some insight into failure of the prediction market to eliminate conversion errors in the \$5.00-\$5.59 segment of fundamental realizations. For the PRED-VIC treatment, summarized in the upper row, notice that when market fundamentals are below $\$ 5.00$ mean ticket prices provide very clear information regarding the social desirability of conversion (in each of these ranges, the mean ticket price is at least 77థ). Similarly for realizations above $\$ 5.59$, the prediction market provides a clear signal that conversion is non-optimal (in these ranges the mean ticket price never exceeds $14 \phi$ ). However, in the $\$ 5.00-\$ 5.59$ range the mean ticket price of 52థ (e.g., a 52\% probability of a conversion) provides essentially no information regarding whether or not a conversion is socially optimal. Thus, given a market fundamental between $\$ 5.00$ and $\$ 5.59$, units trade at prices slightly above $\$ 5.00$ and monitors finds themselves in precisely the same position as their counterparts in a REG-VIC session. Consequently, they err just as frequently.

Similarly, in a value-decreasing condition the prediction market generally provides useful information except the case where such information is most needed. As can be seen in the second row of Table 7, for all PRED-VDC segments below $\$ 5.00$, ticket prices averaged at least $82 \phi$, indicating that conversion should be anticipated. Again, for market fundamentals in segments above $\$ 5.59$, ticket prices average no more than $32 \phi$, indicating that conversion was not efficient. In the $\$ 5.00-\$ 5.59$ range, however, the mean ticket price of $62 \varnothing$ provides very little information either to traders or to the monitor regarding the desirability of a conversion, and in fact errantly suggests that conversion is, on average, warranted.

In summary then, the addition of a prediction market to the Regulator regime improves informational efficiency both under the value-increasing condition and (albeit more modestly) under value-decreasing condition. Nevertheless, the prediction market largely fails to reduce the incidence of conversion errors in the segment where such errors occur with highest frequency in the Regulator regime, because it fails to deliver a clear message to the market regarding the desirability of a conversion just when such a message is most needed.

\subsubsection{Which Regime is Preferable? Our experimental results do not suggest a uniformly} preferred conversion mechanism. Nevertheless, the fixed price rule does have advantages over a discretionary regulator. In the results, the fixed-trigger rule was neither less efficient nor significantly more susceptible to conversion errors than a discretionary regulator, even under the 
best of circumstances. However, under some conditions the sort of errors observed in the FixedTrigger treatment - those concentrated near the $\$ 5.00$ trigger - may be preferable to those generated in the other treatments. Errors under the Regulatory regime were dispersed over a wide range of fundamentals and while the more complicated Prediction regime improved relative to the Regulatory regime, it did not improve upon the Fixed-Trigger regime. Furthermore, both regimes with a regulator are less transparent to participants than a simple fixed trigger rule and might more susceptible to political pressures that were not part of the experiment.

\section{Concluding Comments.}

This paper reports an experiment conducted to evaluate price-dependent rules for triggering contingent capital conversions. We find that if conversion triggers are based on equity prices, the endogeneity between conversions and equity value creates an important informational problem. In the case that a fixed rule is used to trigger a conversion, the problems of equilibrium nonexistence (in a value-increasing condition) and multiple equilibria (in a value-decreasing condition) predicted by $S W$ prominently undermine market performance and induce a high incidence of conversion errors.

Using a regulator to determine conversion based on a price does not eliminate the informational and allocative inefficiencies associated with the use of a fixed conversion trigger. Indeed, sometimes it is worse. When a conversion increases the value of equity, we find that the switch from the use of a fixed price trigger to a regulator leaves informational efficiency largely unaffected, but increases both the number of conversion errors and the range of fundamental realizations over which conversion errors occur, as is consistent with the nonexistence results of $B F$ and $B G P$. Furthermore, in the case of a value-decreasing conversion, the regulator fails to significantly reduce the incidence of traders coordinating on low rather than high price outcomes for market fundamental values and increases the range of instances where conversion errors occur. ${ }^{35}$

\footnotetext{
${ }^{35}$ An interesting question is whether changing the regulator's payoff would improve performance. Mechanisms that bias regulator payoffs have been suggested for dealing with commitment problems in monetary policy, e.g., hiring a central banker who is tough on inflation. In our information transmission problem, it is harder to see how behavior would change. For some ranges of fundamentals, traders may be more confident about the regulator's behavior, but for other ranges less certain. The wide range of fundamentals under which we observed conversion errors for the regulator suggests that changing payoffs will not dramatically improve performance.
} 
Similarly, and contrary to the predictions of $B G P$, supplementing the information provided to a regulator with the results of a prediction market that assesses the likelihood of a conversion does not eliminate conversion errors. The prediction market does improve informational efficiency by encouraging traders to incorporate the value of a conversion into prices when conversion is clearly desirable. However, this improved informational efficiency fails to translate into a low incidence of conversion errors because the prediction market largely fails to provide clarifying information when it is most needed, e.g., when market fundamentals are close to the efficient conversion cutoff.

We interpret these results as strong evidence that contingent capital with a market price trigger has significant costs as measured by informational efficiency, allocational efficiency, and conversion errors. Furthermore, the results indicate that these costs are higher for a regulator than for a fixed-price trigger. The regulatory discretion seems to add uncertainty that interferes with the efficient operation of markets. A prediction market can mitigate the inefficiencies, but it does not improve upon the simple fixed price trigger.

These results do not mean, of course, that conversion should not depend on prices; the alternative of ignoring prices all together may be far worse. Nevertheless, it seems that there are significant costs to using market prices as a trigger, so that to gain the full benefit of contingent capital requires finding a trigger that does not have, or at least reduces, the inefficiencies identified above. 


\section{References}

Admati, Anat, Peter DeMarzo, Martin Hellwig and Paul Pfleiderer. 2010. "Fallacies, Irrelevant Facts, and Myths in the Discussion of Capital Regulation: Why Bank Equity is Not Expensive.” Stanford University Graduate School of Business Research Paper No. 2065.

Anderson, Lisa R. and Charles A. Holt. 1997. "Information Cascades in the Laboratory," American Economic Review 87 (December): 847-62.

Berg, Joyce, Robert Forsythe, Forrest Nelson and Thomas Rietz. 2008. "Results from a Dozen Years of Election Futures Markets Research.” In C. Plott and V. Smith (eds.), Handbook of Experimental Economics Results. Elsevier Science, Amsterdam: 742-51.

Birchler, Urs and Matteo Facchinetti. 2007. "Self-Destroying Prophecies? The Endogeneity Pitfall in Using Market Signals for Prompt Corrective Action.” Manuscript, University of Zurich.

Bond, Philip, Itay Goldstein and Edward Simpson Prescott. 2010. "Market-Based Corrective Actions.” The Review of Financial Studies 23: 781-820.

Calomiris, Charles and Richard Herring. 2011. "Why and How to Design a Contingent Convertible Debt Requirement.” Wharton Financial Institutions Center Working Paper No. 11-41.

Cason, Timothy and Daniel Friedman. 2008. “A Comparison of Market Institutions.” In C. Plott and V. Smith (eds.) Handbook of Experimental Economics Results. Elsevier Science, Amsterdam: 264-72.

Cason, Timothy and Daniel Friedman. 1999. "Price Formation and Exchange in Thin Markets: A Laboratory Comparison of Institutions.” In E. de Antoni, P. Howitt and A. Leijonhufvud (eds.), Money, Markets and Methods: Essays in Honour of Robert W. Clower. Edward Elgar Pub, Mass.

Cason, Timothy N., Lata Gangadharan, and Charlotte Duke. 2003. "Market Power in Tradable Emission Markets: A Laboratory Testbed for Emission Trading in Port Phillip Bay, Victoria.” Ecological Economics, 46 (October): 469-91.

Cowgill, Bo, Justin Wolfers, and Eric Zitzewitz. 2009. "Using Prediction Markets to Track Information Flows: Evidence from Google.” Manuscript, Dartmouth University.

Cummings, Ronald G., Charles A. Holt, and Susan Laury. 2004. "Using Laboratory Experiments for Policy Making: An Example from the Georgia Irrigation Reduction Auction.” Journal of Policy Analysis and Management, 23 (March): 341-63.

Duffy, John and Eric O’N. Fisher. 2005. "Sunspots in the Laboratory.” American Economic Review 95 (June): 510-29.

Flannery, Mark J. 1998. "Using Market Information in Prudential Bank Supervision: A Review of U.S. Empirical Evidence.” Journal of Money, Credit and Banking 30 (August, part 1) 273-305.

Flannery, Mark J. 2005. “`No Pain, No Gain’: Effecting Market Discipline via `Reverse Convertible Debentures’,” in Hal Scot (ed.), Capital Adequacy beyond Basel: Banking, Securities, and Insurance, Oxford University Press, Oxford.

Flannery, Mark J. 2009. "Stabilizing Large Financial Institutions with Contingent Capital Certificates.” Manuscript, University of Florida.

Fischbacher, Urs. 2007. “z-Tree: Zurich toolbox for ready-made economic experiments.” Experimental Economics 10 (February): 171-8.

Forsythe, Robert and Russell Lundholm. 1990. "Information Aggregation in an Experimental Market.” Econometrica 58: 309-47. 
Government Accountability Office. 2011. "Bank Regulation: Modified Prompt Corrective Action Framework Would Improve Effectiveness.” GAO-11-612, June.

Hanson, Robin, Ryan Oprea and David Porter. 2006. "Information aggregation and manipulation in an experimental market.” Journal of Economic Behavior \& Organization 60 (June): 449-59.

Hart, Oliver and Luigi Zingales. 2010. “A New Capital Regulation for Large Financial Institutions.” FEEM Working Paper No. 124.2009.

Hussam, Reshmaan N., David Porter, and Vernon L. Smith. 2008. "Thar She Blows: Can Bubbles Be Rekindled with Experienced Subjects?” American Economic Review 98 (June): 924-37.

Independent Commission on Banking. “Final Report Recommendations.” September 2011.

Kagel, John H. 2004. "Double Auction Markets with Stochastic Supply and Demand Schedules: Call Markets and Continuous Trading Mechanisms.” In S. Hack (ed.), Advances in Understanding Strategic Behavior; Essays in Honor of Werner Guth. Palgrave: New York.

Kagel, John H. and Dan Levin. 1986. “The Winner’s Curse and Public Information in Common Value Auctions.” American Economic Review 76 (December): 894-920.

King, Ronald, R., Vernon L. Smith, Arlington W. Williams, and Mark Van Boening. 1993. "The Robustness of Bubbles and Crashes in Experimental Stock Markets.” In R. Day and P. Chen (eds.), Nonlinear Dynamics and Evolutionary Economics, Oxford: Oxford University Press: 183-200.

Lei, Vivian, Charles N. Noussair, and Charles R. Plott. 2001. "Nonspeculative Bubbles in Experimental Asset Markets: Lack of Common Knowledge Rationality vs. Actual Irrationality.” Econometrica 69 (July): 831-59.

Majluf, Nicholas S. and Stewart Myers. 1984. "Corporate Financing and Investment Decisions When Firms Have Information That Investors Do Not Have.” Journal of Financial Economics 13: 187-221.

McDonald, Robert L. 2011. “Contingent Capital with a Dual Price Trigger.” Manuscript, Northwestern University.

Niederle, Muriel and Alvin E. Roth. 2005. “The Gastroenterology Fellowship Market: Should There Be a Match?” American Economic Review 95 (May): 372-75.

Oprea, Ryan, David Porter, Chris Hibbert, Robin Hanson, and Dorina Tila. 2007. "Can Manipulators Mislead Market Observers?” Manuscript, University of California Santa Cruz.

Pennacchi, George. 2011. “A Structural Model of Contingent Bank Capital.” Manuscript, University of Illinois.

Pennacchi, George, Theo Vermaelen, and Christian C. P. Wolff. 2013. "Contingent Capital: The Case for COERCs.” Manuscript, University of Illinois.

Plosser, Charles. 2010. "Convertible Securities and Bankrutpcy Reforms: Addressing Too Big to Fail and Reducing the Fragility of the Financial System.” Conference on the Squam Lake Report: Fixing the Financial System, Manuscript, June 16.

Plott, Charles R. 2001. "Equilibrium, Equilibration, Information and Multiple Markets: From Basic Science to Institutional Design.” Nobel Symposium on Experimental and Behavioral Economics, Stockholm Sweden. 
Plott, Charles and Timothy C. Salmon. 2004. "The Simultaneous, Ascending Auction: Dynamics of Price Adjustment in Experiments and in the U.K. 3G Spectrum Auction.” Journal of Economic Behavior and Organization 53: 353-83.

Plott Charles R. and Shyam Sunder. 1988. "Rational Expectations and the Aggregation of Diverse Information in Laboratory Security Markets.” Econometrica 56 (September): 1085-118.

Prescott, Edward Simpson. 2012. “Contingent Capital: The Trigger Problem.” Federal Reserve Bank of Richmond Economic Quarterly, Forthcoming.

Raviv, Alon. 2004. "Bank Stability and Market Discipline: Debt-for-Equity Swap versus Subordinated Notes.” http://EconPapers.repec.org/RePEc:wpa:wuwpfi:0408003.

Smith, Vernon L., Gerry L. Suchanek, and Arlington W. Williams. 1988. "Bubbles, Crashes and Endogeneous Expectations in Experimental Spot Asset Markets.” Econometrica 56 (September): 1119-51.

Squam Lake Group. 2010. The Squam Lake Report: Fixing the Financial System. Princeton University Press, Princeton.

Sundaresan, Suresh and Zhenyu Wang. 2011. "On the Design of Contingent Capital with Market Trigger,” Federal Reserve Bank of New York Staff Report No. 448. 


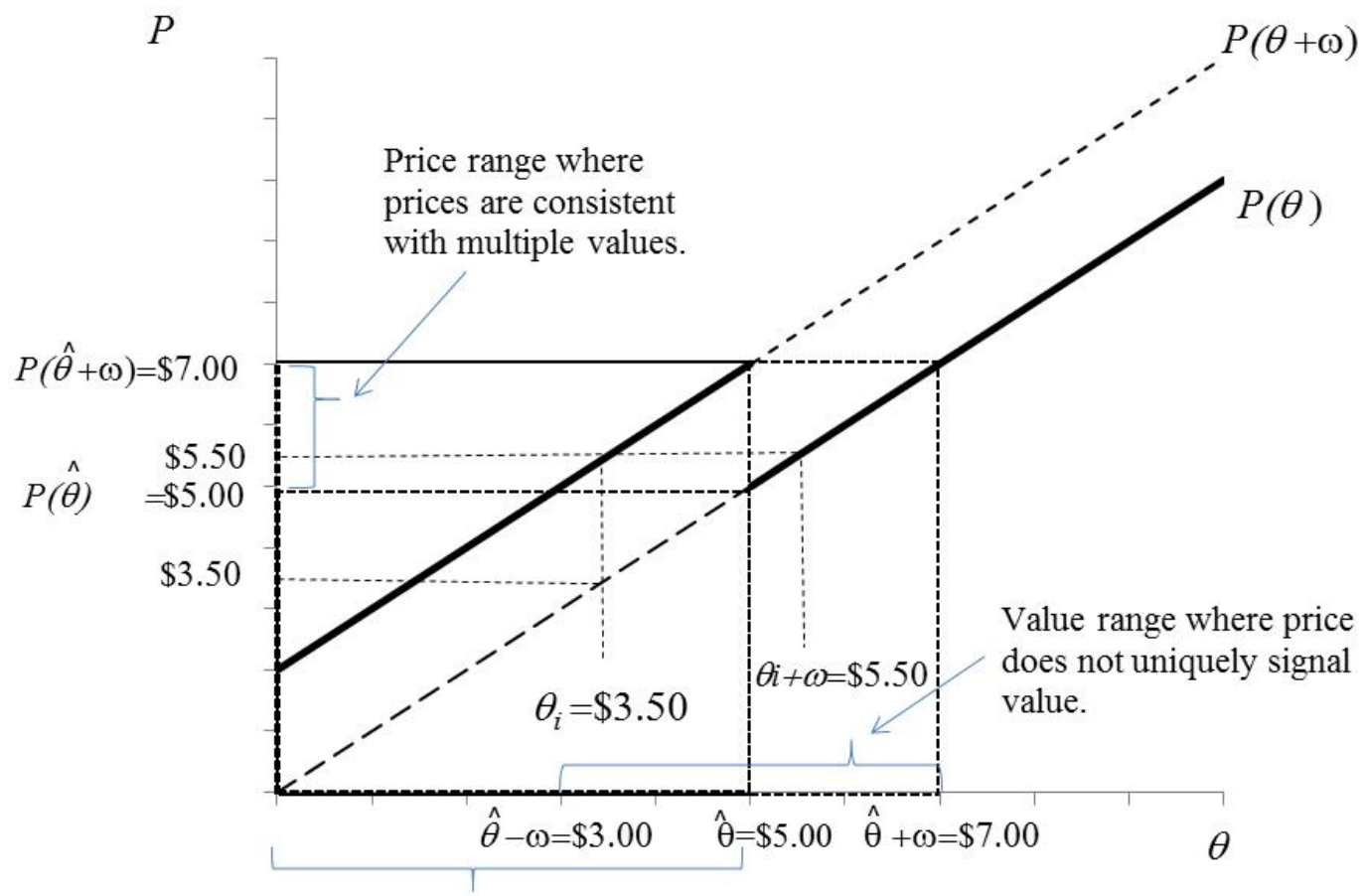

Range of socially desirable conversions

Figure 1. Prices and Fundamentals Given the Possibility of a Value-Increasing Conversion.

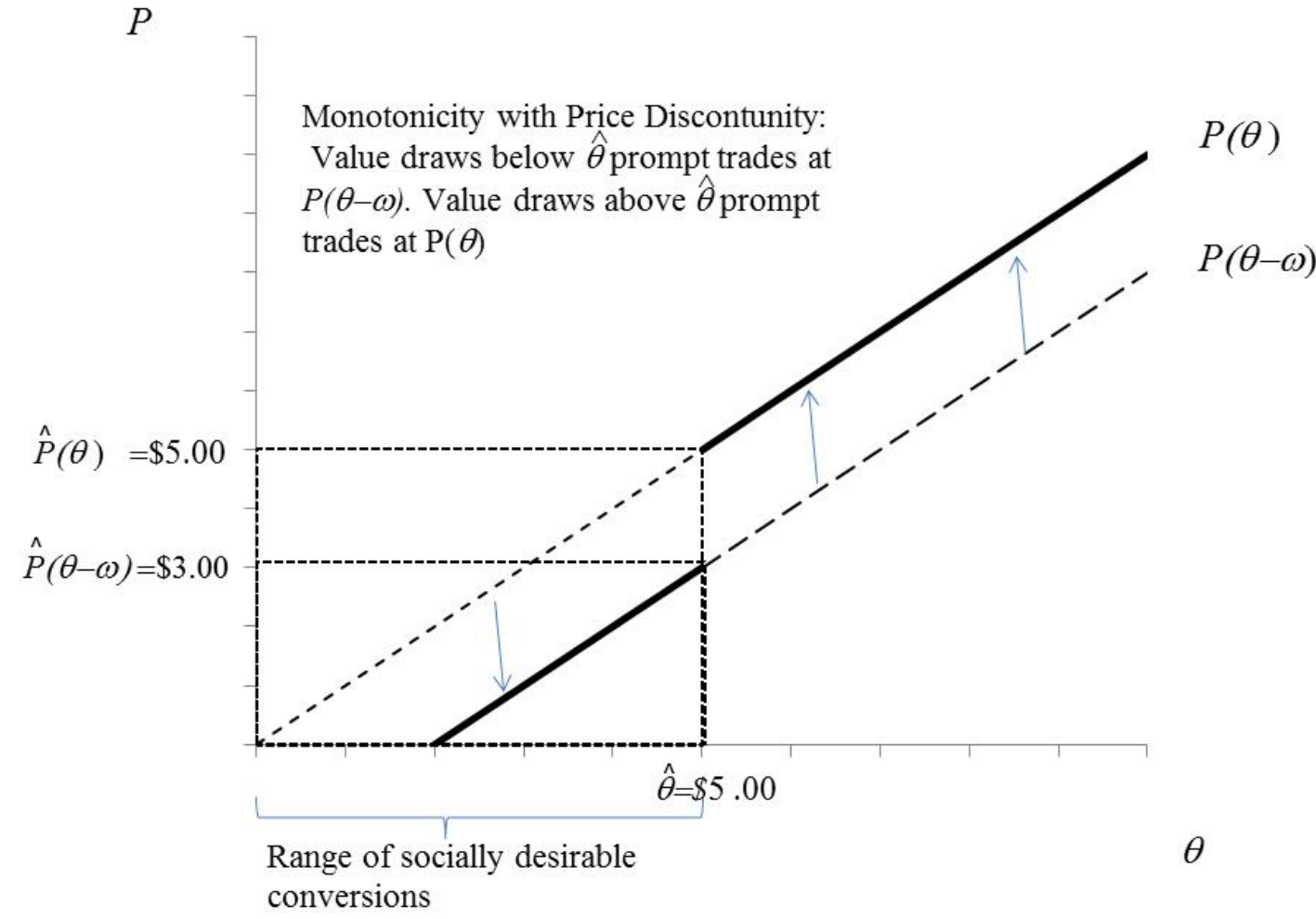

Figure 2. Prices and Fundamentals, Given the Possibility of a Value-Decreasing Conversion. 
Fundamental (Unadjusted)

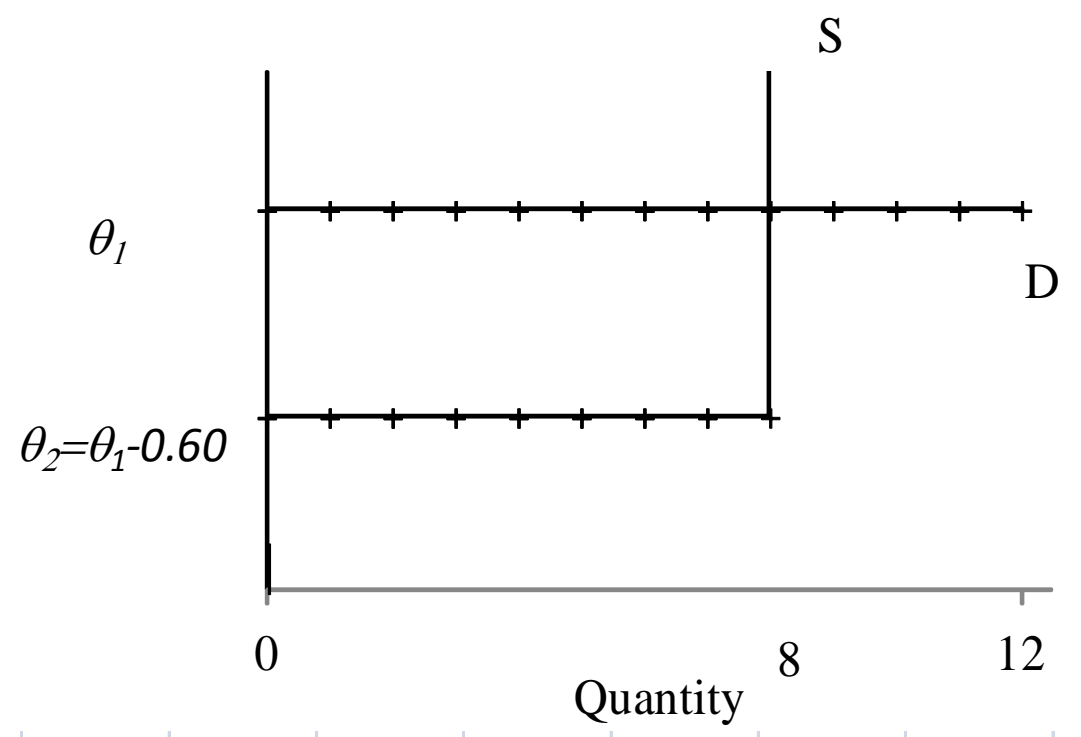

Figure 3. Market Supply and Demand, Given a Market Fundamental $\theta_{1}$. 


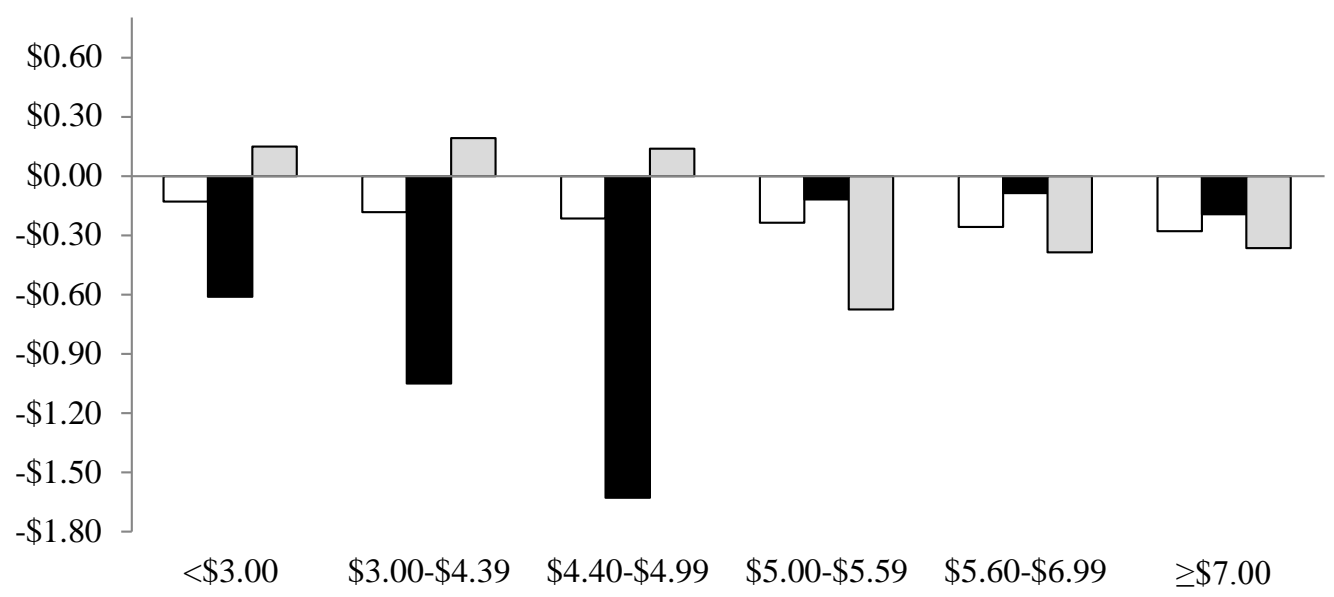

(a) Mean Price Deviations

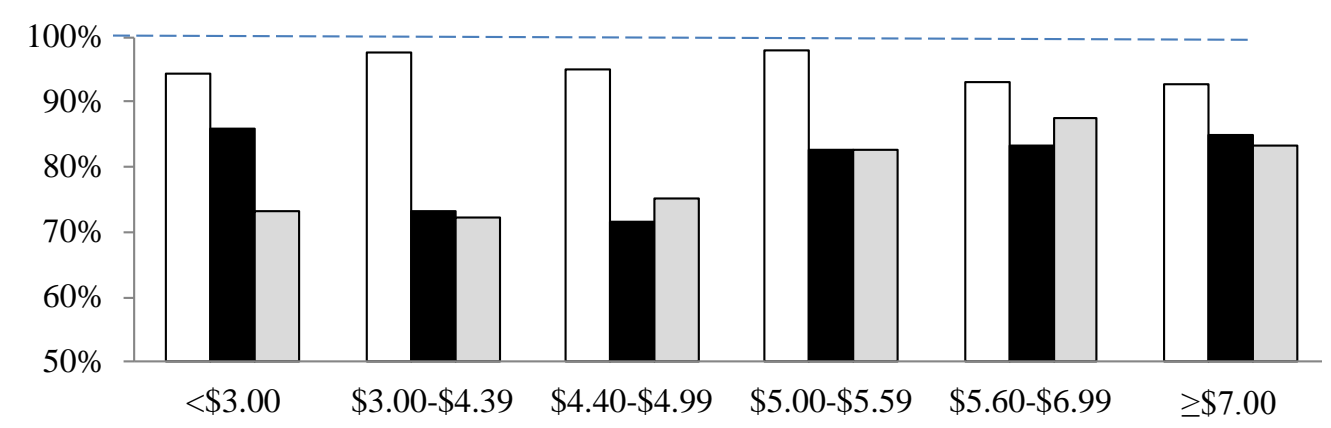

(b) Allocative Efficiency

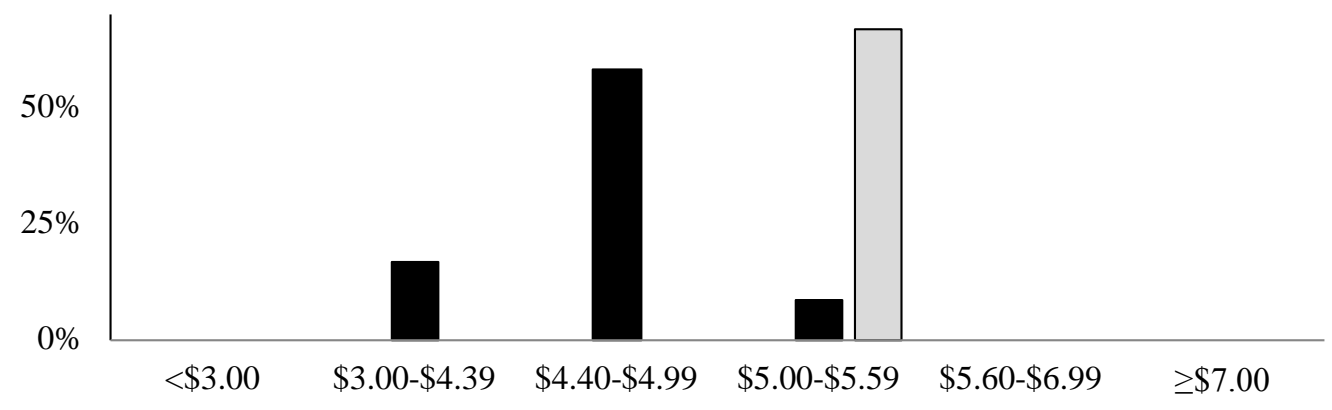

(c) Conversion Error Rates

$\square$ BASE घFT-VIC $\square F T$-VDC

Figure 4. Fixed-Trigger Treatment Results (With BASE). 


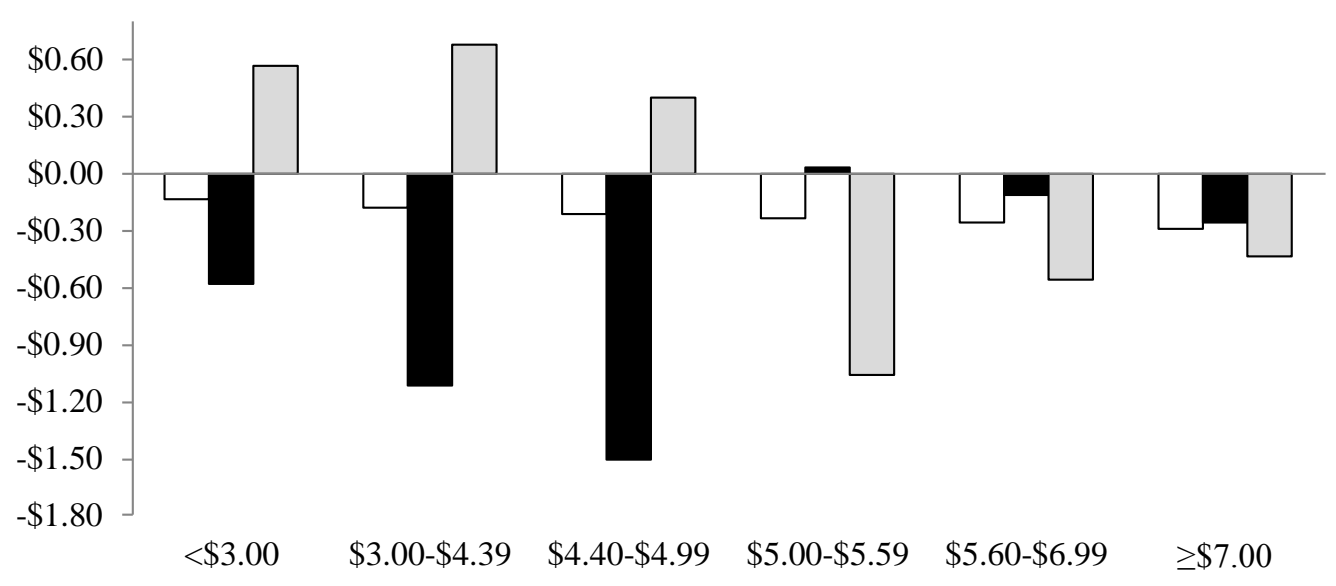

(a) Mean Price Deviations

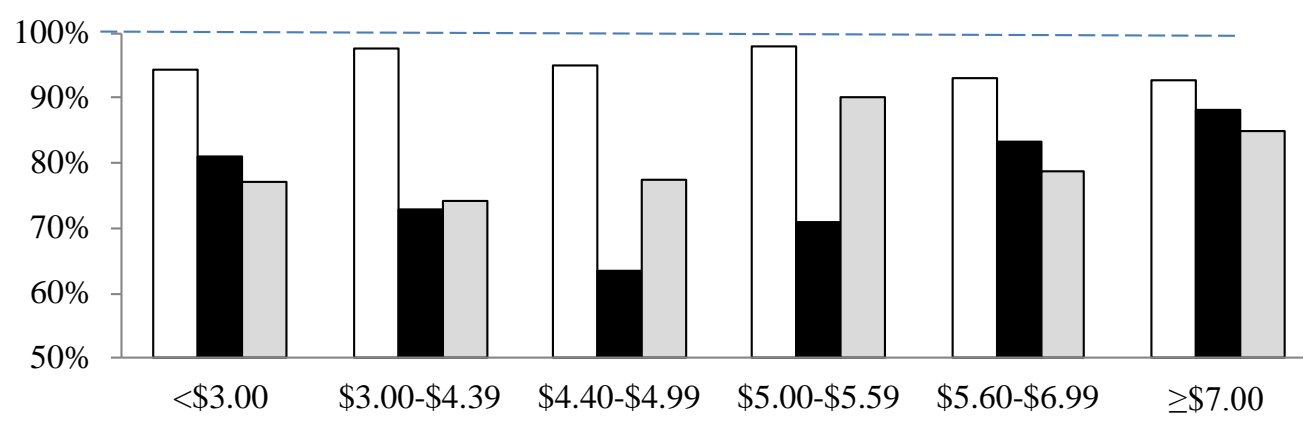

(b) Allocative Efficiency

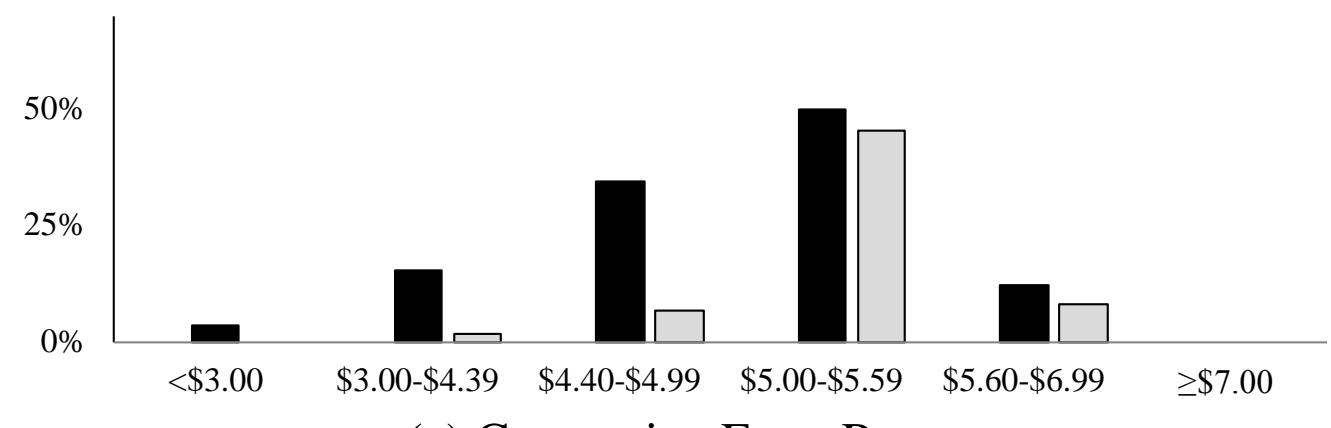

(c) Conversion Error Rates

\section{$\square B A S E \quad \square R E G-V I C \quad \square R E G-V D C$}

Figure 5. Regulator Treatment Results (with BASE). 


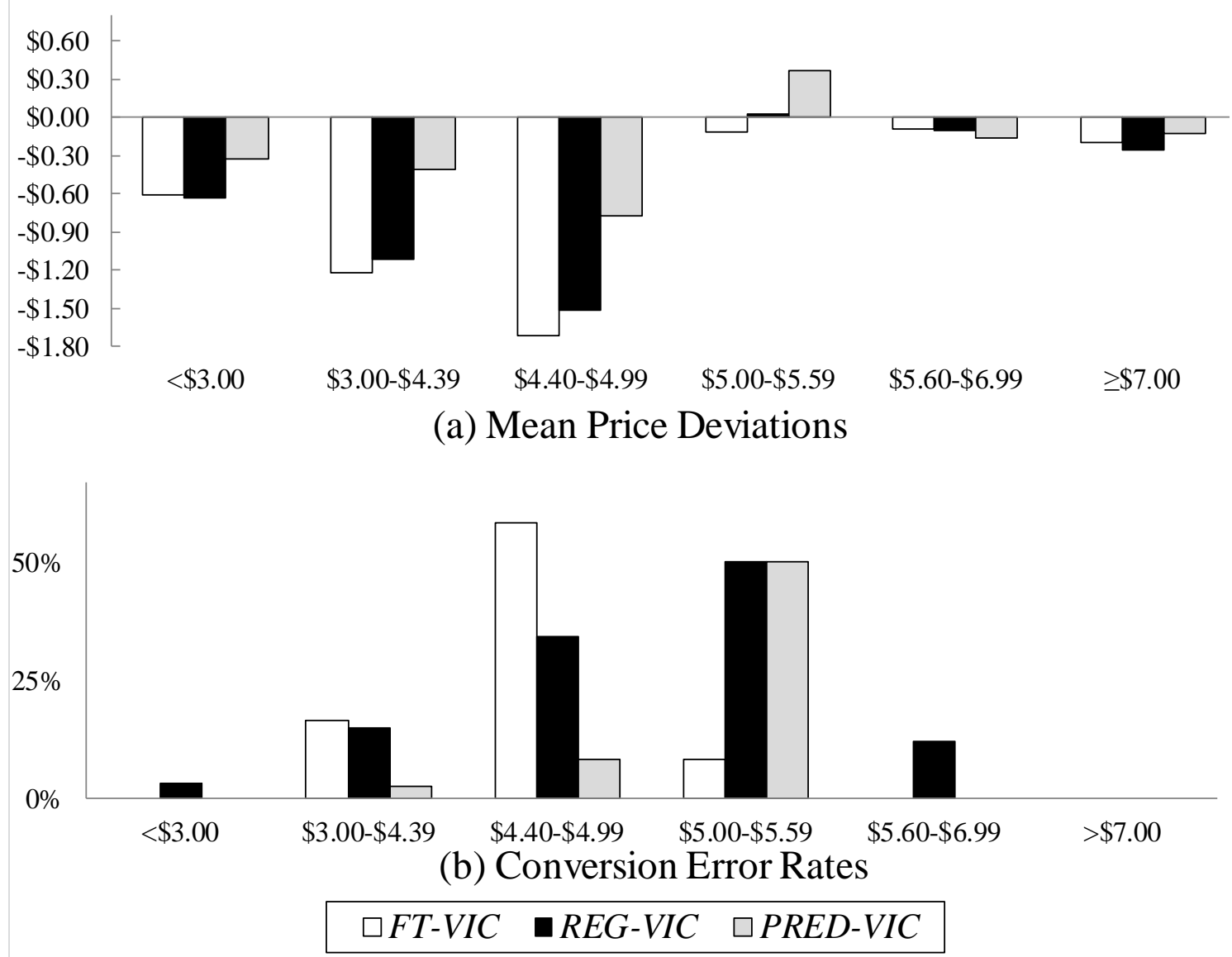

Figure 6. Across Treatment Comparisons, Value Increasing Conversion Condition 

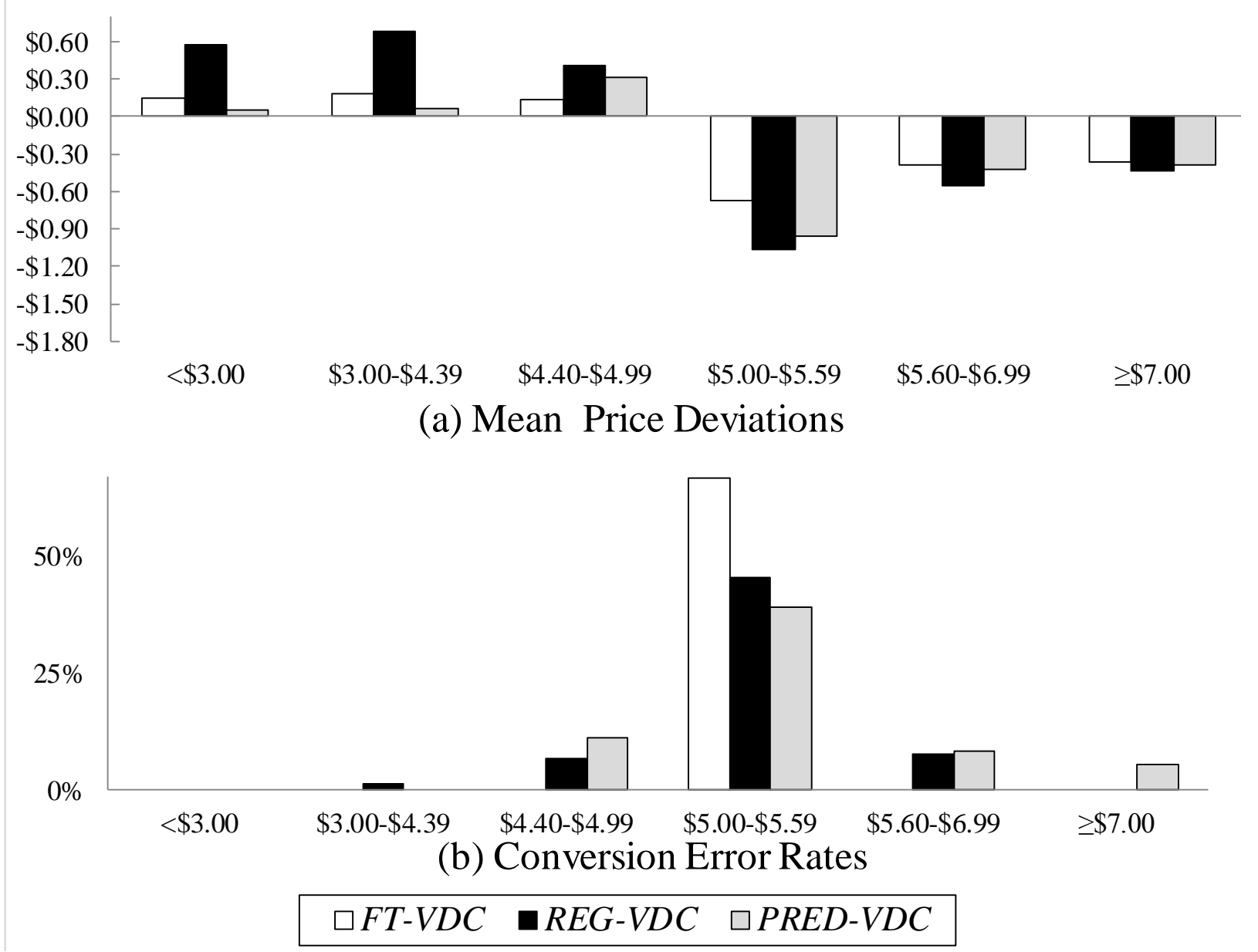

Figure 7. Across Treatment Comparisons, Value Decreasing Conversion Condition 
Table 1. Reference Predictions by Treatment

\begin{tabular}{|c|c|c|c|c|c|}
\hline \multirow[t]{2}{*}{ Treatment } & \multirow[t]{2}{*}{ Conversion Condition } & \multicolumn{4}{|c|}{ Range } \\
\hline & & $<\$ 3.00$ & $\$ 3.00-\$ 4.99$ & $\$ 5.00-\$ 6.99$ & $\geq \$ 7.00$ \\
\hline \multirow[t]{2}{*}{ Fixed-Trigger (SW) } & Value Increasing & $*$ & No Eq. & $*$ & $*$ \\
\hline & Value Decreasing & $*$ & $*$ & Mult. Eq. & $*$ \\
\hline \multirow[t]{2}{*}{ Regulator $(B G P, B F)$} & Value Increasing & * & No Eq. & No Eq. & $*$ \\
\hline & Value Decreasing & * & $*$ & $*$ & $*$ \\
\hline \multirow[t]{2}{*}{ Prediction Market (BGP) } & Value Increasing & $*$ & $*$ & $*$ & $*$ \\
\hline & Value Decreasing & $*$ & $*$ & $*$ & $*$ \\
\hline
\end{tabular}

Key: * Unique Rational Expectation Equilibrium, Mult. Eq.: Multiple Rational Expectations Equilibria, No Eq. - No

Rational Expectations Equilibrium.

Table 2. Experiment Design and Session Progression

\begin{tabular}{|c|c|c|c|c|c|c|}
\hline \multirow[b]{2}{*}{ Session } & \multirow[b]{2}{*}{$\begin{array}{l}\text { Number of } \\
\text { Sessions }\end{array}$} & \multicolumn{5}{|c|}{ Session Structure, by Periods } \\
\hline & & $\underline{1-5}$ & $\underline{6-10}$ & $\underline{11-15}$ & $16-20$ & $\underline{21-25}$ \\
\hline FT-VIC/ FT-VDC & 3 & $\underline{B A S E}$ & \multicolumn{2}{|c|}{$F T-V I C$} & \multicolumn{2}{|c|}{$F T-V D C$} \\
\hline$F T-V D C / F T-V I C$ & 3 & $\overline{B A S E}$ & FT- & & \multicolumn{2}{|c|}{$F T-V I C$} \\
\hline$R E G-V I C$ & 8 & BASE & \multicolumn{3}{|c|}{$R E G-V I C$} & -- \\
\hline$R E G-V D C$ & 8 & $\overline{B A S E}$ & \multicolumn{3}{|c|}{$R E G-V D C$} & -- \\
\hline REG-VIC /PRED-VIC & 6 & $\overline{B A S E}$ & $R E G-V I C$ & \multicolumn{2}{|c|}{ PRED-VIC } & -- \\
\hline$R E G-V D C / P R E D-V D C$ & 6 & $\overline{B A S E}$ & $R E G-V D C$ & \multicolumn{2}{|c|}{ PRED-VDC } & -- \\
\hline
\end{tabular}


Table 3 BASE Condition and FT Treatment: Incremental Differences from BASE Range BASE

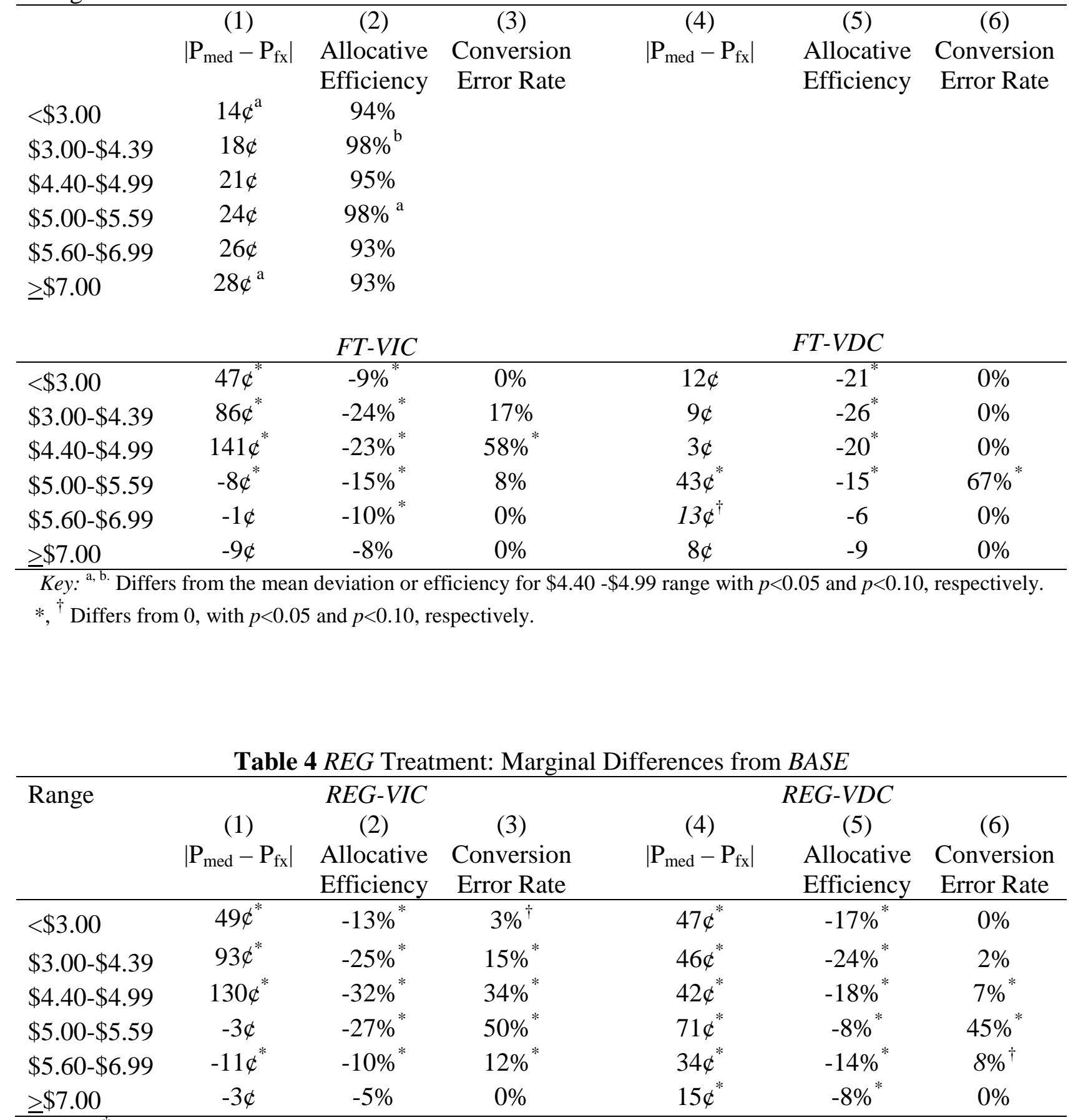

Key: ${ }^{\dagger}, \quad$ Differs from 0 , with $p<0.05$ and $p<0.10$, respectively. 
Table 5 Incremental Effects of REG Markets Relative to FT.

\begin{tabular}{|c|c|c|c|c|c|c|}
\hline \multirow[t]{4}{*}{ Range } & \multicolumn{3}{|c|}{ Value Increasing Conversion } & \multicolumn{3}{|c|}{ Value Decreasing Conversion } \\
\hline & $(1)$ & (2) & (3) & $(4)$ & (5) & (6) \\
\hline & $\left|\mathrm{P}_{\text {med }}-\mathrm{P}_{\mathrm{fx}}\right|$ & Allocative & Conversion & $\left|\mathrm{P}_{\text {med }}-\mathrm{P}_{\mathrm{fx}}\right|$ & Allocative & Conversion \\
\hline & & Efficiency & Error Rate & & Efficiency & Error Rate \\
\hline$<\$ 3.00$ & $2 \phi$ & $-5 \%$ & $3 \%^{\dagger}$ & $34 \varnothing$ & $4 \%$ & $0 \%$ \\
\hline$\$ 3.00-\$ 4.39$ & $7 \phi$ & $-1 \%$ & $-2 \%$ & $36 \phi^{\dagger}$ & $2 \%$ & $2 \%$ \\
\hline$\$ 4.40-\$ 4.99$ & $-12 \phi$ & $-8 \%$ & $-24 \%$ & $39 \phi^{*}$ & $2 \%$ & $7 \%{ }^{\dagger}$ \\
\hline$\$ 5.00-\$ 5.59$ & $5 \not$ & $-11 \%{ }^{*}$ & $42 \%{ }^{*}$ & $27 \phi$ & $8 \%$ & $-21 \%$ \\
\hline$\$ 5.60-\$ 6.99$ & $-10 \phi$ & $0 \%$ & $12 \%{ }^{*}$ & $20 \varnothing$ & $-9 \%{ }^{\dagger}$ & $8 \%^{\dagger}$ \\
\hline$>\$ 7.00$ & $6 \varnothing$ & $3 \%$ & $0 \%$ & $7 \varnothing$ & $2 \%$ & $0 \%$ \\
\hline
\end{tabular}

Key: $*^{\dagger}$ Differs from 0 , with $p<0.05$ and $p<0.10$, respectively.

Table 6. Incremental Effects of PRED Markets Relative to REG

\begin{tabular}{|c|c|c|c|c|c|c|}
\hline \multirow[t]{4}{*}{ Range } & \multicolumn{3}{|c|}{ Value Increasing Conversion } & \multicolumn{3}{|c|}{ Value Decreasing Conversion } \\
\hline & (1) & (2) & (3) & (4) & (5) & (6) \\
\hline & $\left|\mathrm{P}_{\text {med }}-\mathrm{P}_{\mathrm{fx}}\right|$ & Allocative & Conversion & $\left|\mathrm{P}_{\text {med }}-\mathrm{P}_{\mathrm{fx}}\right|$ & Allocative & Conversion \\
\hline & & Efficiency & Error Rate & & Efficiency & Error Rate \\
\hline$<\$ 3.00$ & $-30 \phi^{*}$ & $1 \%$ & $-3 \%^{\dagger}$ & $-37 \phi^{\dagger}$ & $-6 \%$ & $0 \%$ \\
\hline$\$ 3.00-\$ 4.39$ & $-70 \phi^{*}$ & $8 \%$ & $-12 \%^{*}$ & $-41 \phi^{*}$ & $6 \%$ & $-2 \%$ \\
\hline$\$ 4.40-\$ 4.99$ & $-74 \phi^{*}$ & $5 \%$ & $-26 \% *$ & $-21 \phi$ & $0 \%$ & $4 \%$ \\
\hline$\$ 5.00-\$ 5.59$ & $21 \not$ & $-8 \%$ & $0 \%$ & $2 \not$ & $-3 \%$ & $-6 \%$ \\
\hline$\$ 5.60-\$ 6.99$ & $1 \varnothing$ & $-1 \%$ & $-12 \%^{*}$ & $-17 \phi$ & $10 \% *$ & $0 \%$ \\
\hline$>\$ 7.00$ & $-12 \phi^{*}$ & $-6 \%$ & $0 \%$ & $-4 \varnothing$ & $1 \%$ & $6 \%$ \\
\hline
\end{tabular}

Key: $*^{\dagger}{ }^{\dagger}$ Differs from 0 , with $p<0.05, p<0.10$, respectively

Table 7. Prediction Markets: Mean Ticket Prices (Standard Deviation)

\begin{tabular}{|c|c|c|c|c|c|c|}
\hline & \multicolumn{6}{|c|}{ Fundamental Range } \\
\hline & $<\$ 3.00$ & $\$ 3.00-\$ 4.39$ & $\$ 4.40-\$ 4.99$ & $\$ 5.00-\$ 5.59$ & $\$ 5.60-\$ 7.00$ & $>\$ 7.00$ \\
\hline PRED-VIC & $93 \nsubseteq(3 \nsubseteq)$ & $85 \nsubseteq(16 \nsubseteq)$ & $77 \$(10 \$)$ & 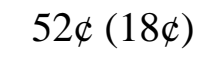 & $14 \pitchfork(10 \nsubseteq)$ & $10 \nsubseteq(6 \nsubseteq)$ \\
\hline PRED-VDC & 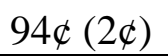 & $82 థ(19 \pitchfork)$ & $83 \pitchfork(9 \pitchfork)$ & $62 థ(20 \notin)$ & $32 థ(19 \$)$ & 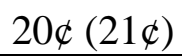 \\
\hline
\end{tabular}


Appendix

Sequences of Fundamental Realizations

Table A1. Sequence of Fundamental Value Realizations REG Sessions

\begin{tabular}{|c|c|c|c|c|c|c|c|c|}
\hline \multicolumn{9}{|c|}{ BASE Condition } \\
\hline Period & 1 & 2 & 3 & 4 & 5 & & & \\
\hline Fundamental & $\$ 2.94$ & $\$ 7.33$ & $\$ 4.76$ & $\$ 2.61$ & $\$ 6.50$ & & & \\
\hline \multicolumn{9}{|c|}{ Regulator Periods } \\
\hline Period & 6 & 7 & 8 & 9 & 10 & 11 & 12 & \\
\hline Fundamental & $\$ 5.73$ & $\$ 3.77$ & $\$ 2.61$ & $\$ 7.39$ & $\$ 5.99$ & $\$ 3.49$ & $\$ 5.74$ & \\
\hline Period & 13 & 14 & 15 & 16 & 17 & 18 & 19 & 20 \\
\hline Fundamental & $\$ 4.54$ & $\$ 7.69$ & $\$ 2.82$ & $\$ 4.73$ & $\$ 6.33$ & $\$ 2.53$ & $\$ 5.31$ & $\$ 4.54$ \\
\hline
\end{tabular}

Table A2. Sequence of Fundamental Value Realizations - FT and PRED

\begin{tabular}{ccccccccccc}
\hline Period: & 1 & 2 & 3 & 4 & 5 & 6 & 7 & 8 & 9 & 10 \\
Sequence & & & & \multicolumn{7}{c}{ Fundamental } \\
\hline A5 & 6.56 & 4.80 & 2.86 & 5.55 & 3.73 & & & & & \\
B5 & 6.49 & 3.81 & 5.45 & 2.82 & 4.71 & & & & & \\
& & & & & & & & & & \\
A10 & 6.82 & 3.34 & 4.83 & 6.14 & 5.23 & 2.92 & 5.44 & 7.16 & 4.70 & 3.72 \\
B10 & 2.94 & 4.52 & 7.29 & 5.27 & 3.73 & 4.49 & 6.27 & 3.63 & 6.37 & 5.17 \\
\hline
\end{tabular}

Table A3. Fundamental Realization Sequences for Prediction and Fixed-Trigger Markets

\begin{tabular}{cccccc}
\multicolumn{8}{c}{ PRED } \\
\hline BASE & REG & VIC & VDC & Sessions \\
A5 & B5 & A10 & & 3 \\
B5 & A5 & B10 & & 3 \\
A5 & B5 & & A10 & 3 \\
B5 & A5 & B10 & 3 \\
& & FT & & & 3 \\
\hline A5 & & A10 & B10 & 3 \\
B5 & & B10 & A10 & \\
\hline
\end{tabular}


Table A4. Absolute and Average Price Deviations, Value Increasing Conversions

\begin{tabular}{|c|c|c|c|c|c|c|}
\hline \multicolumn{7}{|c|}{ (1) Average Absolute Price Deviations, $\left|\mathrm{P}_{\mathrm{med}}-\mathrm{P}_{\mathrm{fx}}\right|$} \\
\hline & $<\$ 3.00$ & $\$ 3.00-\$ 4.39$ & $\$ 4.40-\$ 4.99$ & $\$ 5.00-\$ 5.59$ & $\$ 5.60-\$ 6.99$ & $\geq \$ 7.00$ \\
\hline BASE & 0.14 & 0.18 & 0.21 & 0.24 & 0.26 & 0.28 \\
\hline FT-VIC & 0.61 & 1.04 & 1.63 & 0.16 & 0.24 & 0.19 \\
\hline REG-VIC & 0.63 & 1.12 & 1.51 & 0.21 & 0.14 & 0.25 \\
\hline PRED-VIC & 0.33 & 0.41 & 0.77 & 0.42 & 0.16 & 0.13 \\
\hline \multicolumn{7}{|c|}{ (2) Average Price Deviations $P_{m e d}-P_{f x}$} \\
\hline & $<\$ 3.00$ & $\$ 3.00-\$ 4.39$ & $\$ 4.40-\$ 4.99$ & $\$ 5.00-\$ 5.59$ & $\$ 5.60-\$ 6.99$ & $\geq \$ 7.00$ \\
\hline BASE & -0.13 & -0.18 & -0.21 & -0.24 & -0.26 & -0.28 \\
\hline FT-VIC & -0.61 & -1.04 & -1.63 & -0.11 & -0.09 & -0.19 \\
\hline REG-VIC & -0.63 & -1.12 & -1.51 & 0.03 & -0.10 & -0.25 \\
\hline PRED-VIC & -0.33 & -0.41 & -0.77 & 0.37 & -0.16 & -0.12 \\
\hline \multicolumn{7}{|c|}{ Absolute Differences between (1 and (2) } \\
\hline & $<\$ 3.00$ & $\$ 3.00-\$ 4.39$ & $\$ 4.40-\$ 4.99$ & $\$ 5.00-\$ 5.59$ & $\$ 5.60-\$ 6.99$ & $\geq \$ 7.00$ \\
\hline BASE & 0.01 & 0.00 & 0.00 & 0.00 & 0.00 & 0.00 \\
\hline FT-VIC & 0.00 & 0.00 & 0.00 & 0.04 & 0.16 & 0.00 \\
\hline REG-VIC & 0.00 & 0.00 & 0.00 & 0.17 & 0.04 & 0.00 \\
\hline PRED-VIC & 0.00 & 0.00 & 0.00 & 0.05 & 0.00 & 0.01 \\
\hline
\end{tabular}

Table A5. Absolute and Average Price Deviations, Value Decreasing Conversions

\begin{tabular}{lrrrrrr}
\hline \multicolumn{7}{c}{$(1)$ Average Absolute Price Deviations, $\left|\mathrm{P}_{\mathrm{med}}-\mathrm{P}_{\mathrm{fx}}\right|$} \\
\hline & $<\$ 3.00$ & $\$ 3.00-\$ 4.39$ & $\$ 4.40-\$ 4.99$ & $\$ 5.00-\$ 5.59$ & $\$ 5.60-\$ 6.99$ & $\geq \$ 7.00$ \\
BASE & 0.14 & 0.18 & 0.21 & 0.24 & 0.26 & 0.28 \\
FT-VDC & 0.26 & 0.27 & 0.24 & 0.67 & 0.39 & 0.37 \\
REG-VDC & 0.61 & 0.64 & 0.64 & 0.94 & 0.59 & 0.43 \\
PRED-VDC & 0.24 & 0.23 & 0.43 & 0.96 & 0.42 & 0.39
\end{tabular}

(2) Average Price Deviations $\mathrm{P}_{\mathrm{med}}-\mathrm{P}_{\mathrm{fx}}$

\begin{tabular}{lrrrrrr}
\hline & $<\$ 3.00$ & $\$ 3.00-\$ 4.39$ & $\$ 4.40-\$ 4.99$ & $\$ 5.00-\$ 5.59$ & $\$ 5.60-\$ 6.99$ & $\geq \$ 7.00$ \\
BASE & -0.13 & -0.18 & -0.21 & -0.24 & -0.26 & -0.28 \\
FT-VDC & 0.15 & 0.19 & 0.14 & -0.67 & -0.39 & -0.37 \\
REG-VDC & 0.57 & 0.58 & 0.53 & -0.94 & -0.59 & -0.43 \\
PRED-VDC & 0.05 & 0.07 & 0.32 & -0.96 & -0.42 & -0.39 \\
& \multicolumn{7}{c}{ Absolute Differences between $(1$ and $(2)$} & & \\
\hline & $<$ B & $\$ 3.00-\$ 4.39$ & $\$ 4.40-\$ 4.99$ & $\$ 5.00-\$ 5.59$ & $\$ 5.60-\$ 6.99$ & $\geq \$ 7.00$ \\
BASE & 0.01 & 0.00 & 0.00 & 0.00 & 0.00 & 0.00 \\
FT-VDC & 0.11 & 0.09 & 0.10 & 0.00 & 0.00 & 0.00 \\
REG-VDC & 0.03 & 0.06 & 0.11 & 0.00 & 0.00 & 0.00 \\
PRED-VDC & 0.19 & 0.16 & 0.11 & 0.00 & 0.00 & 0.00 \\
\hline
\end{tabular}

